\title{
AUTOETHNOGRAPHIC JOURNEY TO DISCOVER THE HEART AND ART \\ OF MY NURSING PRACTICE
}

\author{
by
}

\section{Peter John Kimble}

A thesis submitted to the Victoria University of Wellington in partial fulfilment of the requirements for the degree of Master of Arts (Applied) in Nursing

Victoria University of Wellington

2010 


\section{ABSTRACT}

This thesis presents an autoethnographic study of the concept of 'compassionate listening' within my general and palliative care practice. I examined my care for people in critical life course moments to gain insight into the process of listening with compassion. This insight evolved through a process of layered reflection using a series of texts, particularly stories that captured critical moments in working with people who were facing crisis situations or who were dying. Writing and reflecting on these stories enabled me identify how I engaged with patients and their loved ones. I was able to explore how compassionate listening could be used to ascertain their needs, particularly when they were unable or unsure how to proceed. Compassion implies the capacity to acknowledge another human's suffering or predicament. Compassionate listening is a form of active listening that begins with the intention to be present for the person. It brings humanness, patience, an acknowledgement of one's own vulnerability and a willingness to interact with a person in a meaningful way that could alleviate some of their suffering. During this special encounter both nurse and patient reach an embodied knowing.

In studying this aspect of caring I chose stories from my practice that were written over a number of years in different locations. I reflected again on these stories to gain deeper insight and asked colleagues to read some of the texts and give me feedback on my practice. Their comments were a valuable part of this layered reflective process. This thesis presents eight stories and a series of reflections on those stories and colleague's comments, which enabled me to explore compassionate listening as it evolved in my practice. This study contributes to an understanding of how the ability to develop refined awareness of meaningful interactions with people can enhance wellbeing for both the patient and nurse.

Keywords: compassion, listening, reflection, meaning, nurse-patient relationship, life course, narrative. 


\section{DEDICATION}

I would like to thank my wife Wendy for standing by me throughout the process leading up to and including this thesis. She is the love of my life, my rock and my soul partner. I would also like to thank my children for understanding when I was busy with my studies and witnessing me steadily going bald from behind as I sat at the computer for countless hours.

\section{ACKNOWLEDGEMENTS}

I would also like to acknowledge my parents and brothers. It was by witnessing compassion in a family sense that formed the background to my value system. To Kevin my youngest brother who died so suddenly at the age of thirty nine whilst this thesis was in progress. Thank you for the happy memories and your larger than life giving personality. We will meet again. To Dad who died before the thesis was completed. I lost not only a father but my best friend. Your lessons on life will live with me forever. To Mom who has always encouraged me and believed in my work.

To Dr.Margi Martin my supervisor. You are a special light in the world of understanding life and the true spirit of nursing. You have made an incredible journey possible. Margi has encouraged my individual unique way of being within nursing's body of knowledge and our healing engagement with humanity.

To Professor Cheryl Moss for encouraging my thesis in its infancy.

To Associate Professor Pamela Wood for her guidance, kindness and patience in enabling me pick up the pieces of what was left of my fragile ego trying to pull the final stages of my thesis into a congruent whole. Your gentle encouragement enabled me to bring the work to completion.

To Dr Kathy Nelson for fine tuning the ethics process for me. 
To those behind the scenes at the Victoria University of Wellington who make studying more seamless such as Abbey McDonald and Justin Cargill. To the librarians of the Waikato District Health Board for their assistance and friendliness and to Denise Irwing who constantly encouraged and assisted me when things seemed to go awry. To the Waikato District Health Board for encouraging me to further my nursing education.

To my nursing colleagues reading and reflecting on parts of my thesis. Your thoughts, sharing and time are greatly appreciated.

To all my patients and their families and loved ones for sharing your suffering and stories with me. Thank you for allowing me to share those special moments of healing and being healed with you and allowing me to hitch a short ride on your life journeys.

To the countless number of nurses and fellow health professionals that I have been privileged to work alongside in my life course. I will always be in awe of your efforts to care for the traumatised, the sick and the dying. 


\section{Table of Contents}

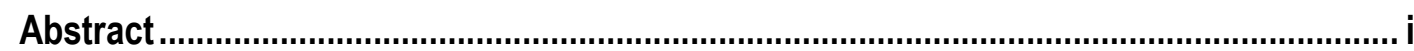

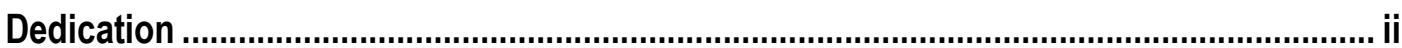

Acknowledgements...................................................................................................... ii

CHAPTER ONE: INTRODUCTION TO THE THESIS ....................................................... 1

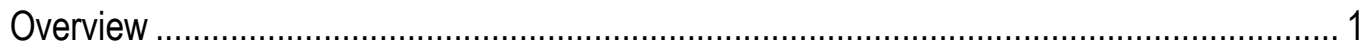

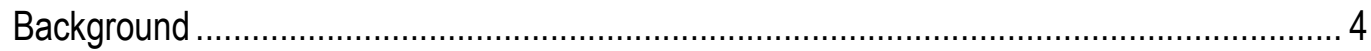

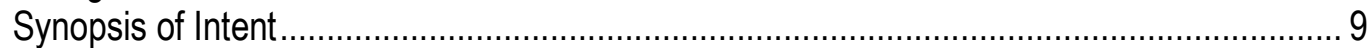

CHAPTER TWO: COMPASSIONATE LISTENING ..................................................... 12

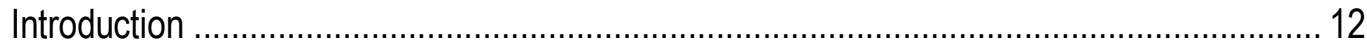

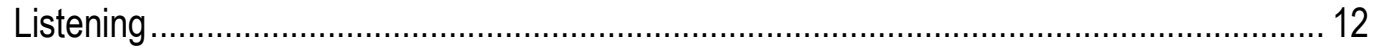

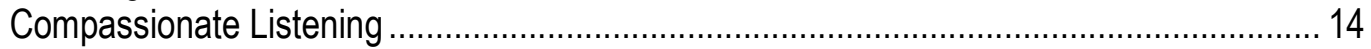

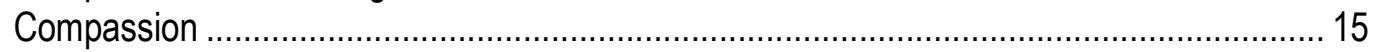

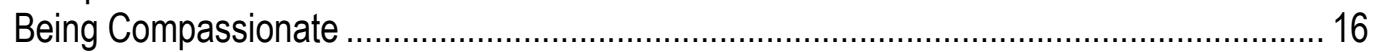

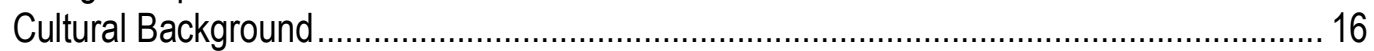

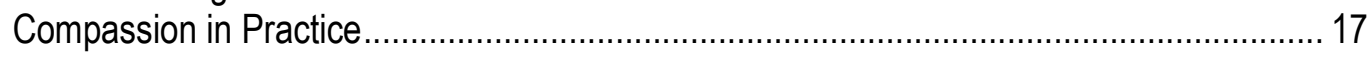

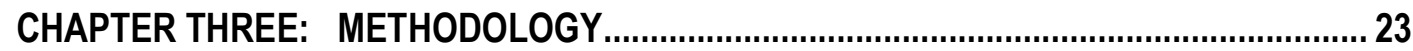

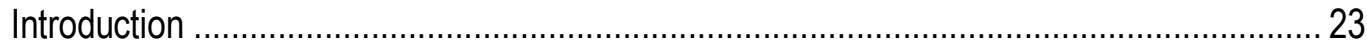

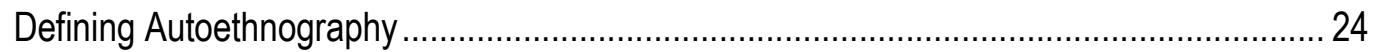

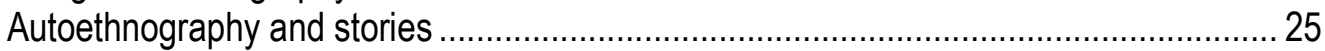

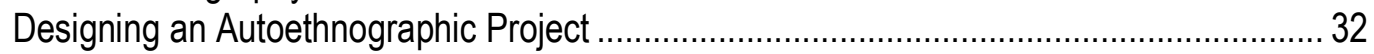

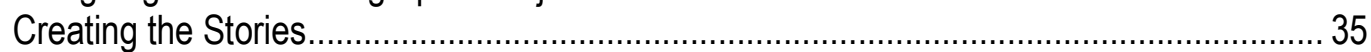

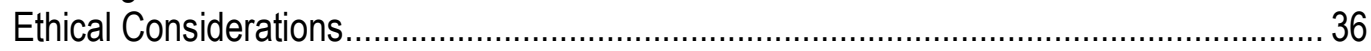

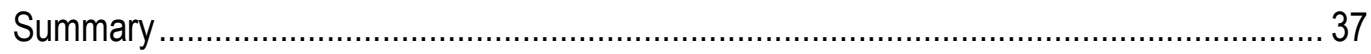

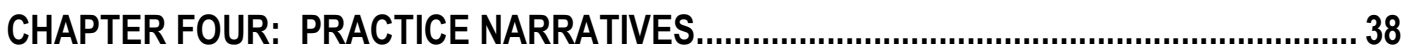

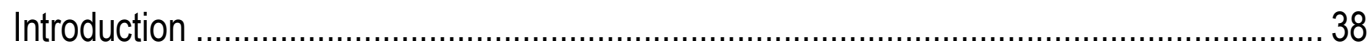

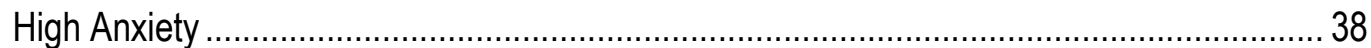

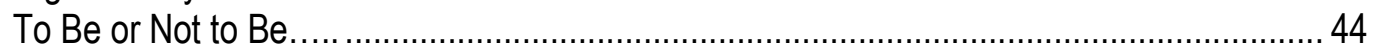

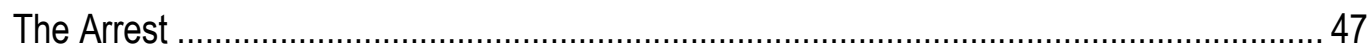

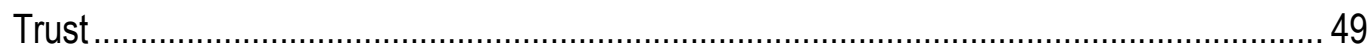

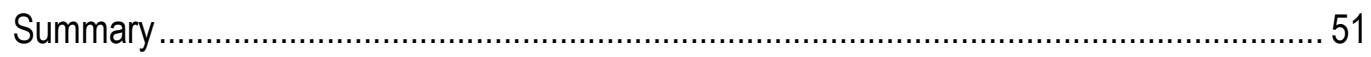

CHAPTER FIVE: TRANSITIONS IN A NURSE'S LIFE STORY ..................................... 52

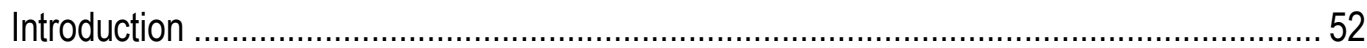

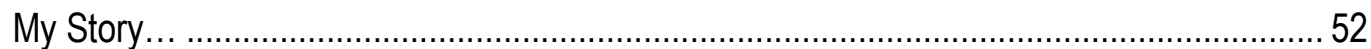

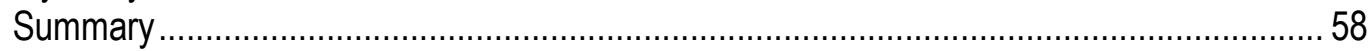

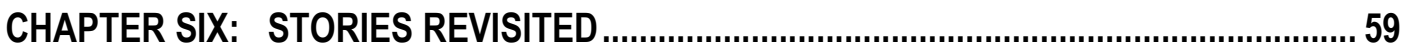

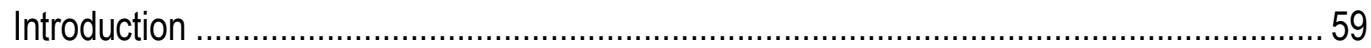

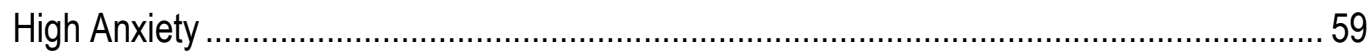

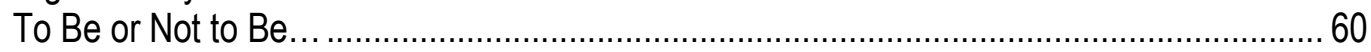




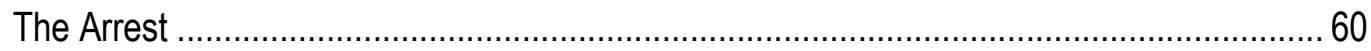

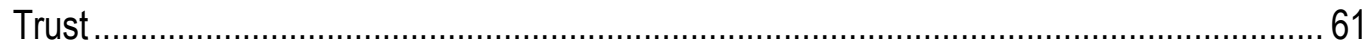

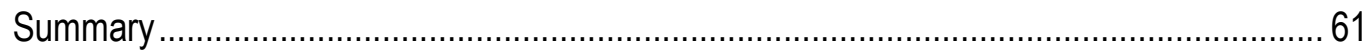

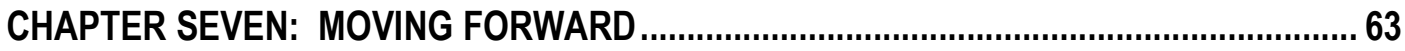

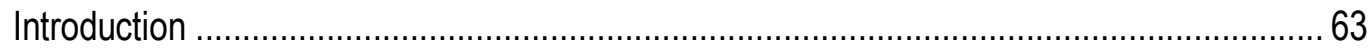

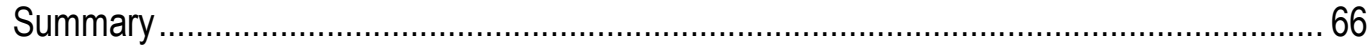

CHAPTER EIGHT: STORIES MOVE ME

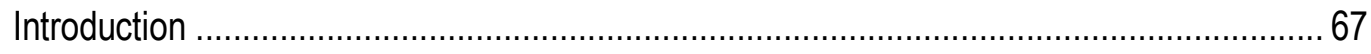

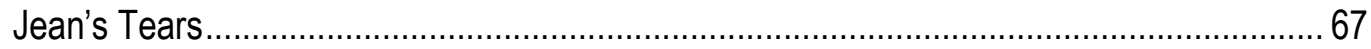

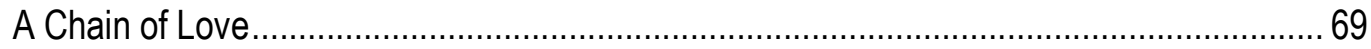

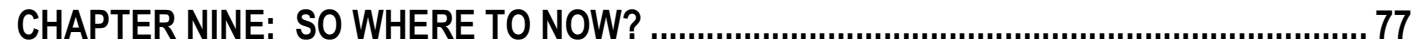

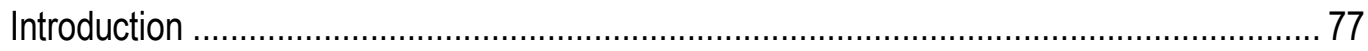

Do My Stories And Reflections Strike A Chord In Other Nurses Or Is This Writing Just About

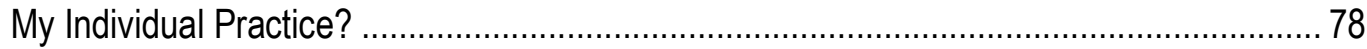

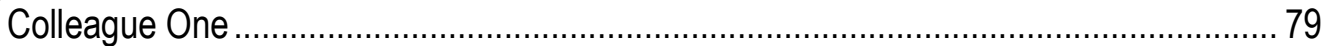

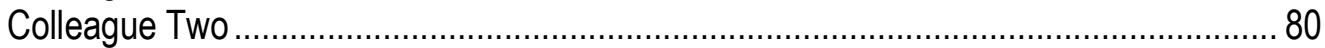

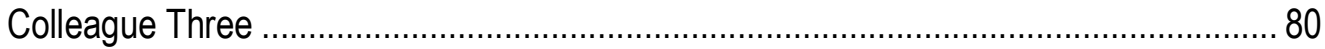

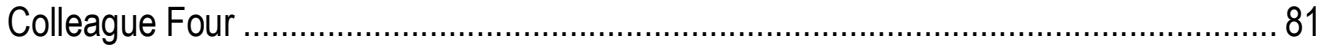

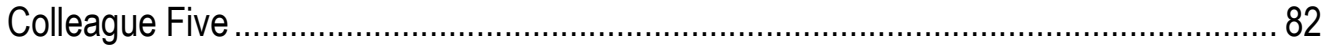

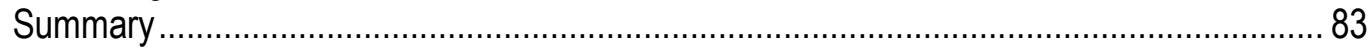

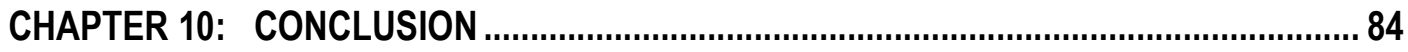

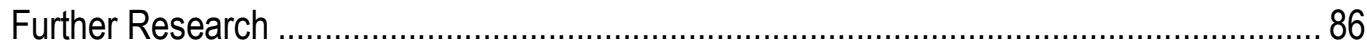

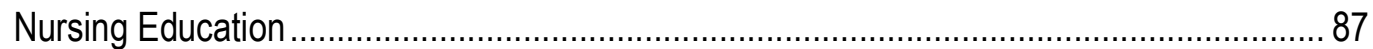

Complete the Chain of Caring with Compassion ............................................................ 88

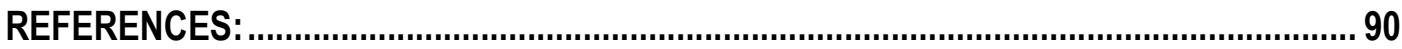




\section{CHAPTER ONE: INTRODUCTION TO THE THESIS}

\section{Overview}

There are many times that a nurse will ponder about what they are achieving. Is what they are doing making any difference in the overall scheme of things? Such thoughts surface during quiet reflection that occurs when I look back over a challenging time in practice. I regard this as a positioning moment that enables me to effectively find order in the diversity of day to day practice.

In nursing the challenges that every nurse faces are often considered to be the same universally or recognisably similar no matter one's culture or practice. The challenges are due to the foundational nature of care being offered between human beings to sustain life during difficult times, most notably during times of profound transition in the life journey such as birth, life altering diseases and traumas and death. I recognise the need to have a strong sense of my own life story to continue to practise and care as a professional over my working life time in my chosen career of nursing. According to Susuki (as cited in Johns, 2006, p. 20), "When you are you, you see things as they are, and you become one with your surroundings. There is your true self. There you have true practice."

Nurses, I believe, have to have a strong sense of their own story in order to cope with the day to day environment where other people's life challenging situations are the focus of almost every interaction with a patient and therefore core to health services. The term 'coping' is common in daily conversation with colleagues. I ask staff how they are 'coping' when I am inquiring as to how they are managing themselves in the work setting. I am seeking a conversation with them about how they are in themselves, how they are managing the situations they are encountering and how they are in their life journey. I challenge myself to do more than cope in my work life and what I am really assessing is how I or a colleague are managing our professional and personal integrity.

It is this sense of being whole that enables me to be compassionate and able to listen to the person and ascertain their needs. Building the capacity to cope creatively as a nurse is an 
individual challenge that underpins competence. Evolving a means of becoming self reliant as one advances one's practice has huge implications for shaping hard won qualities in the health service such as compassion and love. Johns (2006) supports this with the following words:

Being mindful; the art of paying attention to self within the unfolding moment, conscious of how self is thinking, feeling and responding yet focused on realising a particular vision of practice. (p.132)

This thesis presents an autoethnographic exploration, using a documentary text reflection on my own life and the people in my practice, to reveal how I have become cognisant of my own core humanitarian values and how these values shape my day to day clinical practice. This style of narrative research using a process of layered reflections has validated the language which I use in conversing with people as I nurse them. It has given me an awareness of my capacity to consciously use narrative to act as a substantive guide in critical moments of care for both myself as a nurse and the patient.

In this thesis I will explore how I fathom the deep inner story that is present in each patient and how I use compassionate listening to reveal insight into being human and human needs. This assessment enables me to address the person's existential as well as physical needs in a critical time. A life course journey is described as having transitions and turns (Daaleman \& Elder, 2007). In life challenging situations there is a transition and often a turning point and hence an opportunity to witness the deep inner story of a person's life journey.

What I am interested in exploring is how I have used compassion to achieve turning points especially with people who are in or facing extreme crisis situations and especially when they are unable or unsure how to proceed. The role of the nurse then is to create a bridge through the event and to ease suffering.

At the heart of this thesis is how compassionate listening occurs in my practice. I realised I needed to make explicit the way compassion and listening were expressed in the personal and professional journey I have made as a nurse. Initially I saw compassionate listening occurring at the end of the stories I have written, but the process of reflecting, philosophising and considering deeply what I was actually doing in critical moments of practice awakened my own 
consciousness. I could see how I would begin the engagement in the proactive moment, with a shift from ordinary consciousness as I was moving through the corridors in the hospital, to one of compassion as I arrived and became present in the person's room. I could then identify that compassionate listening was an intention. I felt a rise of awareness of this energy that I recognised as being focused and able to care for another with compassion. This process did not occur spontaneously but over time. At first I grappled with listening. How do I as a nurse listen? Was I paying attention to the patient or to the detail of the task at hand? I realised that to listen properly I had to be attentive, present and focused. Then I pondered on how difficult it seemed to focus when my mind was racing with so many other physical needs that had to be met.

I had read about compassion and witnessed profound moments of compassion over my life's journey. I believed that what I witnessed in the busy world around me did not portray much focus on compassion. I often heard that nursing is a caring profession but caring compassionately was not what I always encountered in day to day practice. There were certainly moments of compassion that I witnessed but I believed it should be a gold standard of nursing practice. I had written assignments and given a few talks on active listening and some on compassion and the loneliness of patients, especially when dying. It was during a lecture during a research paper when I found my mind wondering about a thesis topic that it dawned on me suddenly that compassion and listening fitted together rather well and even had a certain reality about them as compassionate listening. I started to intentionally focus on compassionate listening as a means to more fully engage with my patients and their families.

The concept of intentionality is central to Kreiger's (2002) research in which she identifies intention as the motivating force to heal. This concept is also described theoretically (Pilkington, 2009) as an expression of the integration of mind-body-spirit. I do associate the experience of intentionality in practice as the embodied sensation of being in the right place at the right time and being able to manifest the right actions. This level of awareness of this process of gaining access to moulding my physical, mental and spiritual self at certain points, integrating the awareness, has occurred through writing and describing my practice insights to colleagues. 
This expression of reflection in and on my practice (Schon, 1983) as it has occurred has enabled me to have an ability to understand the nature of insight and to appreciate that this is a gift that has to be nurtured in oneself. I wanted to express the art of practice which is what I saw and experienced when a certain buzz was occurring weaving together a chaotic medical or surgical emergency situation into a meaningful and spiritual whole. This buzz occurs when the realisation hits me that something more than physical healing and observation is taking place. I wanted to be able to explain how I was able to 'think on my feet' which was the term used by Schon (1983). I could really see and feel the truth in Schon's (1983) description of an expert practitioner:

The practitioner allows himself to experience surprise, puzzlement, or confusion in a situation which he finds uncertain or unique. He reflects on the phenomenon before him, and on the prior understandings which have been implicit in his behaviour. He carries out an experiment which serves to generate both a new understanding of the phenomenon and a change in the situation. ( $p$. 68)

I realized that I had used insight to awaken my own consciousness so that I could begin the shift with compassion and listening as an intention. This process of being conscious of being intentional has enabled me to have an ability to understand the nature of my experience of insight.

\section{Background}

I have been nursing for close to thirty years and have always been intrigued by why as nurses we continue our work while witnessing so many gut wrenching and terrible events. Not only do our visual memories of bloody traumas remain, but we see the suffering of patients, their families and loved ones on an almost daily basis. My interest in what happens began with dealing with my own experiences.

Since then I have become mindful of the wealth of research that can inform practitioners once they themselves are mindful that there is a need to evolve their own capacity to work in such 
settings. Research is diverse and includes insights on vicarious traumatisation (Pack, 2008) and compassion fatigue (Vachon, 1987). I am aware that New Zealand nursing colleagues have contributed research to specialised areas such as mental health and occupational health nursing where such knowledge of professional self care is considered to be foundational, peer supported and a sign of a mature professional (Hughes, 2006; Maher, 1999 ; Puckey, 2001). Nursing practice has long been influenced by research into effects of stress on health and behaviour (Selye, 1976). The way in which nurses can reflect on their practice and write their own narrative using autobiography as a means to gain and record skilful engagement in their practice has emerged as a nursing research project (Johnstone,1999). Notable examples of nursing colleagues, autoethnographies are Kidd (2008) and Levine (2006).

In the past decade research using a process of reflection on one's own practice has been described by eminent nurse researchers such as Taylor (2004), Johns (1999), Freshwater, Taylor and Sherwood, (2008) and in an international scholarly collective invited to deliver a position statement on reflective practice for Sigma Theta Tau, an organisation that was founded in 1922 at Indiana University to promote nursing as a science and as a profession. Their descriptions collectively indicate that this process of reflection is acceptable as a professional means to develop the capacity to practise effectively and is a hallmark of nurses who describe how they have advanced their expertise. The Nursing Council of New Zealand (2007) competencies enshrine the term reflection. But, what does reflection look and feel like in one person's work life as a nurse? Is there a disciplined approach to developing competence? Can I document how my practice evolves and as a result come to know what gives me the authority to say that I am an expert practitioner?

The nature of this development at a personal level began as a mystery to be explored. In identifying my slow journey I have used the thesis to describe how I have discovered the depth of my practice. I have not self proclaimed this as evidence of my expertise but instead have sought conversations with colleagues and shared my practice with them by inviting their comments. This has resulted in an amazing experience of being affirmed both in my demonstrated practice and in feedback on the narrative descriptions of what it is that I do and how I think in practice. I see now in reading my own text and seeing the impact this text has on 
colleagues that I can express my thinking and am regarded as being thoughtful and able to consider difficult situations. I smile when I realise that my designated role in a large acute setting was to troubleshoot challenging situations.

I realise in being offered this role some years ago, senior colleagues could already see my capacity while I somewhat more slowly have become able to articulate the expertise I have as a nurse. To be articulate about what one does is of course universally what one sees in others whom one admires as being competent and creative professionals. But to become expert requires challenging oneself to always seek excellence in the activity of the day. The activity for me will always be engaging with patients and families in critical moments of their life and engaging with colleagues who are also thrust into these settings.

Through the process of conducting an autoethnographic project to explore compassionate listening in my practice world, I have discovered that I can express my practice as 'expert clinical knowledge'. This has been largely writing texts and reflections and sharing these with colleagues. I recognise that this 'talk' about the work encompasses both my ways of being as a clinician and my ways of knowing what to do and how to be in critical moments of caring for another. It was this search for how to express what I was seeing and then thinking in critical moments that I termed 'the mystery' of practice.

Having reflected on my life journey and choices I have made, I usefully identified a series of steps that I took to be able to position my practice in the present day. As I related to colleagues I began to be inspired in my own practice when I read text written by articulate others. But this text could only be written after I had revisited these inspired writers. It was as if I was thinking and feeling through their texts and I began to find the way through language to what was occurring. Philosophers such as Frankl (2006) and Roach (1984) enabled me to generate my own thoughtfulness which I expressed in philosophical and rhetorical questions. For instance I credit their style of thinking with my generating the question - how does one make space for magic to happen in the practice world which is so pressured? Asking questions enabled me to identify what I was curious about and then I became more alert in practising to notice when what I was doing aligned with my interest. 
The next step was articulating my life and work in South Africa and when I came to New Zealand as an immigrant. This autobiographical text in Chapter Five identifies my cultural heritage and indicates how it has shaped my present life. I had an upbringing in a challenging country and landscape that profoundly shaped my life course and is an important part of this autoethnography. I regard this step of writing my life as a story as being crucial to my sense of professional integrity. I credit being articulate about my life as providing me with the ongoing impetus and courage to be creative in the actual moment of practice when challenging situations are occurring.

In the third stage of the journey in the thesis I reveal my interest in the experience of insight and relationships and the capacity to be more fully connected as a human being with others. I offer some thoughts on insight as an embodied capacity in the expert practitioner through my experience of engaging with colleagues around texts that we have been writing together as we each explore our practice. I wrote practice narratives initially as texts to enable me to focus on the actual words that I was using in the practice moment and then reflected on them over a period of time in between writing my own life story and experiencing the loss of my own brother in a sudden death. Over this time I realised that I could articulate the process of my own thinking in practice. The thesis is presented as a journey and a collation of my own texts and reflections. I have documented the style of conversations I have with colleagues in the thesis. This enabled me to have insight into the nature of relationships in practice and the role of compassion and the act of listening.

Provocative questions that I used for contemplation over thirty years of practice arose from my reading of different writers such as Frankl (2006). How do we find meaning as described by Frankl when we work in what seems to be a quagmire of varying degrees of suffering? What makes so many of us go back for more day after day, month after month, year after year? What assists us to explore humanity with another human being who is suffering so that we find some connection, some glue that makes the whole exercise worthwhile? I have found such questions give me a core strength or resilience (Phanouf, 1976) as I practise in an era and environment when health care is managed as a commercial enterprise. In the corporate health system units of cost matter and behind the scenes nurses and physicians determine if illness is 
treatable with a whole range of parameters in mind. In the corporate model there is scant or no emphasis in the work setting on the basic human needs of those providing health care and this possibly might explain why basic needs such as quiet and peace are not a high priority and therefore simply not available for patients and families.

The macro context is framed by constant restructuring and audits which do not question nurses on how individuals maintain well being in the ever demanding profession of nursing which is focused on caring for the actual patient and their family. What keeps the vision of nursing as a practice obvious as an embodied practice? This is currently modelled by experts and mentored in an obvious way for novices (Benner, 2001) or nurses in training. What occurs to foster the spirit of nursing in those nurses who will follow in expert nurses' footsteps? These questions were also generated by Benner (2001) and have played on my mind from when I began this project. In completing the text I now am able to recognise both a journey and the steps I have been through as a developmental process.

Nursing is identified as a "helping profession" by Shaw and Degazon (2008) and nurses are distinguishable from other colleagues with whom I work in the multidisciplinary health teams by the unique nature of their frequent contact and dialogue with patients. Much has been written about the caring aspect of nursing by nurses such as Watson $(1999,2005)$, Roach(1984, 1987, 1997) and Benner(1984) and I would like to explore further focusing on what initiates the space that enables caring in my own practice? I want to begin by literally observing myself in practice, reflecting on my actions and documenting what I am doing as I establish this space of caring. I realise that as I begin I can already see that there is a knowing about the need to make a space for caring to occur. I am very aware as I practise that what I do in practice is commented on as being different. While I choose how I practise, I am interested in what this difference might be. Possibly what I am endeavouring to achieve in my practice is healing the unique human being that I interact with, suffer with and learn from. I try to focus on what is going on for the person not only what his physical signs and symptoms are.

Healing in modern western medicine is concerned with physical functionality. Dossey and Dossey (1999) indicate that "nurses are at the vanguard of the quickening of the transpersonal 
currents in healing" (p. viii). I would agree. Healing in modern western health settings appears to focus more on physical functionality, but in fact nursing leaders such as Watson (1999) have questioned this approach. I see the reality day to day of what makes the difference to patients and their families. Watson moves us forward by stating that "health care to be complete must focus more on doing-it must also address matters of being" (1999, p.viii).

\section{Synopsis of Intent}

This autoethnographic study explores how compassionate listening is revealed in my practice. I wanted to reveal to myself how compassion exists in critical moments of care and how compassion is linked to a certain style of listening that impacts on the outcome of care. I wanted to hold this as a form in my practice and see if I could identify what I was doing to create the space for compassionate listening. This concept is explained more in Chapter 2.

I found myself making this space in my mind first with awareness of the bigger picture of being human and suffering. And then I associated this call for the bigger picture with a concern for how nurses conduct themselves collectively in their complex and hurried work life. I knew in myself that something had occurred to enable me to practise and I presumed that this must be the case for colleagues and that something also enables them to continue. They are faced with limited resources and witness and share in tough human scenarios of suffering, anxiety, grief and loss. How do we continue to promote that crucial aspect of nursing as being profound and important rather than an expression of work that is too challenging? How do nurses continue to function in an era that places ever increasing demands on them?

If we don't practice as society sees us, that is as caring professionals, then eventually we may lose the legislative right to practise. This is perhaps where the comment stems from that nurses could be replaced with people like technicians who do not have care as one of the legislated domains in their practice.

The focus of this thesis was not the political spheres of practice or even the policies and management in the health system, although these areas of course are key in senior nurses' work worlds. I wanted to focus rather on the reality that many nurses feel fulfilled and find 
meaning in their practice in spite of the difficulties they face. My observation is that when nurses connect with a patient and there is meaning in this connectedness with another human being, then they gain the satisfaction of realising that they have made a difference.

Conducting research from within one's practice was new to me so I evolved a series of steps in a project format that enabled me to learn about the method for discovery of practice as I wrote. I discovered I had to become very careful about articulating the sentinel questions I was asking as these questions signalled how I was observing myself in practice.

Ellis's (1996) insights about writing one's own life story and the way that this enabled her to gain insight into autoethnography as a methodology provided me with a map for my life story and the tone of writing in the text in which one's own voice is very strong and clear. Frankl's (1959) concept of meaning provided me with a sense of continuously finding purpose .Roach's (1984) premise that "caring is the human mode of being" revealed to me the interconnection between my hands on practice and the deepest inner story about life as it is lived. Sandelowski's (1994) paper "We Are the Stories We Tell. Narrative Knowing in Nursing Practice" provides me with the confirmation that story is a valid means of reflecting on and advancing one's practice. Each of these writers enabled me to clarify the need to tell the story of my practice evolution through a process of identifying the questions I was asking and sharing through writing my own story. This process is described in more detail in Chapter 3.

I describe my own life journey as an autoethnographic text in Chapter 5 and identify some specific experiences and encounters that shaped who I was and indeed am as a nurse. It was most interesting to discover that indeed these profound experiences had shaped my practice today and that I had had insights as a result of these experiences.

The process of developing capacity through insight requires a systematic and disciplined engagement with oneself as a narrator of one's own life story. So the exhortation to be empathic that I had heard in my training could be restated at this point as 'practice is made perfect through a process of being able to systematically and continually reflect, reflect, reflect'. Just exactly how one developed capacity through this process evaded me at this beginning 
point when I asked the question! And how I got to develop insight was even more elusive. I had, like many colleagues in contemporary nursing settings, written exemplars of my practice and felt a range of emotions as I presented them to colleagues and educators and professional auditors. While the goal is to demonstrate one's professional capacity, the actual exercise on the surface seems somewhat pointless until one engages in it wholeheartedly. It is not until one makes a way into the heart of oneself as a person and weaves one's own life story alongside the stories of times spent with patients and really fully describes the meaningful outcomes for both them and oneself that one sees and feels what practice as an expert nurse means in context. The thesis reveals this process. And I do feel confident of my ability to describe the process through which I gain insight in relation to my own practice.

I have written many texts over time but have chosen to present eight narrative stories that represent moments and that have had a profound impact on me. They also show a sequence of how I developed an ability to reflect on my practice. The texts have been fictionalised to protect the identity of people involved in clinical settings. The objective was to take this kind of situation and find a way to see the inner dynamic of what was occurring between me and the patient and others in the setting. I have chosen the texts and then engaged deeply with them by considering them in relation to qualities that exist in expert practitioners' practice i.e. compassion and the ability to listen. These stories are presented in Chapters 4, 7 and 8 . Nurse colleagues' reflections on them are presented in Chapter 9.

In the next chapter I document my initial exploration of the motivations of listening and compassion as I found that I was inarticulate about these terms and needed to find a way to describe what I was seeing. 


\section{CHAPTER TWO: COMPASSIONATE LISTENING}

\section{Introduction}

Although caring and compassion are acknowledged by nursing scholars as being integral to nursing practice (Roach, 1987: Watson, 1985) little in depth research on the nature of compassion in nursing has occurred about this focal part of nursing. This was validated by Schantz (2007) who indicated "It is noteworthy, however, that while caring (or compassion) is identified as nursing's most precious asset, nursing research (or discourse) featuring the profession's altruistic ideals is not only scarce, but also lukewarm at best." ( $p .49)$

In this chapter I present my reflections on compassion particularly in relation to listening.

\section{Listening}

"Genuine listening means suspending memory, desire and judgement, and - for a few moments at least - existing for the other person" (Burkhart, 2006, p.58.).

Listening is a key component of communication. It is through this form of communication that I develop a human to human relationship with the patient. This activity perhaps more than anything else creates a bond of trust between nurse and patient. Without listening to the patients' needs, the planning of patient care becomes a one-sided prescriptive affair. There is no partnership in the relationship and this in turn negatively impacts on the healing process the patient experiences.

According to Travelbee (1971):

the role of the nurse needs to be transcended in order to perceive and relate as human being to human being, instead of nurse to patient. It is only in human to human relatedness, which means transcending roles, that a relationship is established. (p.33) 
It is this act of choosing to transcend what we immediately perceive through engagement in listening that is central. Not acting to make this shift is described as poor listening and this lack of engagement will negatively affect the development of the therapeutic relationship between nurse and patient. Travelbee (1971) stresses the importance of the nurses' "therapeutic use of self" which she defines as: "the ability to use one's personality consciously and in full awareness in an attempt to establish relatedness and to structure nursing intervention" (p.19). This intervention brings about change which in turn alleviates the patient's distress.

It is important that the form of listening that is occurring between nurse and patient is recognised fully. It is not considered to be a passive act that can be learned in a short space of time and is also more than casual conversation where most of the talking could be undertaken by the nurse with scant regard to what the patient is trying to communicate. The attention to the moment is described in nursing as being present in the situation for the other. According to Taylor( as cited in Stickley \& Freshwater ,2006) "being present or being human is the primary concern of nursing practice and can be made explicit through listening" (p.14).

Exactly how I move into being fully present with the patient is central and I value being able to feel what is occurring. Taylor (as cited in Stickley \& Freshwater, 2006) states that: though listening may only be achieved when the nurse creates the therapeutic space within the relationship to give him or herself the opportunity to experience the emotions and feelings in the here and now, to further facilitate relating to patient as person. The ability to listen to others entwined with the ability to listen to oneself. (p.14)

Being able to feel what is occurring I have termed 'active listening' as opposed to not listening and not being present with intention; this is most important when initially engaging the patient and relatives. Without active listening how do I as a nurse know what is going on for the patient and relatives? Part of my role as a nurse is to advocate on behalf of patients. If I don't hear their voices and identify their feelings because I have not listened then how can I know what I need to advocate for on their behalf? 
When patients feel they are being listened to they respond and give a nurse insight into their (the patients') being, their uniqueness, their fears and joys. As trust develops this sharing of mutual humanity can become deeper. By listening I am responding to the patient's emotional needs of being noticed, respected and valued. When and if I reach the deeper levels of shared humanity, the deep inner stories, then I consider that I can encounter the spiritual being of this person. This sharing of the uniqueness and awareness of self goes beyond the physical experience of life and the constraints of science. The bare essence of our humanity in regards to other humans and our relationship with the world and the universe can be revealed. In this sharing there is a connectedness of spirit. Our uniqueness as well as our connectedness to each other and the universe is revealed and explored.

As a health professional one of my challenges is to encourage emotional and spiritual health as well as physical health. Active listening and being present for the patient enables exploration of these emotional and spiritual needs. My challenge is to be able to respond accordingly in the moment which can only occur if I am fully present through listening to the person and their feelings.

\section{Compassionate Listening}

In my experience and after reflecting on this deeply, I consider compassion to be the precursor to active listening and the caring moment. I have pondered the question of how nurses show they care in everyday nursing since my days as a student nurse. I have come to the realisation that it is through compassion that we reach that space unique to our humanity where we are able to identify with another person to show that we care. Through compassion one is able to strip off the layers that hide our core human nature. We remove layers such as detachment, showmanship, superiority, competition and ego and according to Nouwen, McNeill and Morrison (1980) "to go where it hurts, to enter into the places of pain, to share brokenness, confusion, and anguish" (p.4).

When patients face illness and suffering they often experience anxiety and vulnerability. If they are in a hospital situation they feel even more vulnerable as they do not have their usual environment and props to support them. According to Nouwen et.al, (1980): "Compassion 
means full immersion into the condition of being human" (p.4). The patient will often want to share their pain and/or anxiety with a fellow human traveller. They sometimes want to explore their own frailty and humanness with another. This interaction is more likely to occur with a nurse who appears warm and compassionate than with someone who seems aloof and busy with a myriad of tasks. Nurses are often so busy with the chores of nursing and coping with resource issues that very little emphasis appears to promote meaningful interactions with patients. I know that nurses are aware that they are witnessing patients' suffering as it often comes up for discussion in the tea room or at the nurses' station. My question in these discussions is often - did you listen to the person and what did they say?

\section{Compassion}

What often comes to mind when contemplating compassion is suffering. According to Nordman, Kasen and Errikkson (as cited in Johns \& Freshwater,1998, p.163), "Health and suffering converge deep down in man's inner entity, which is expressed by his body soul and spirit." It is natural to avoid suffering and to flee when encountering suffering of some kind. To be compassionate entails a shift from one's own space into the space of another. Being present for that person means trying to alleviate or share the burden of illness, anxiety or pain. To share suffering is to share in our common frail humanity. "The word compassion is derived from the Latin words pati and cum which together mean to suffer with"( Nouwen, et al, 1983, p.4). According to Barasch (2009) compassion's "root meaning is 'to suffer with', compassion challenges our tendency to flinch away from life's too tender parts whether those parts belong to us or to others" (p.7).

Human caring is integral to nursing practice (Benner \& Wrubel, 1989 ; Watson, 1983). Out of all the discussion around caring and nursing the writings of Roach (1991) resonate for me as a nursing professional. Roach conceptualizes caring "as the human mode of being and goes on to state that "Caring is the expression of our humanity, and it is essential to our development and fulfilment as human beings" (p.7).

As a nurse, it is tempting to claim caring as unique and distinguishing to nursing but this is hardly the case as Roach (1991) again highlights: 
Nursing is no more and no less than the professionalization of the human capacity to care through the acquisition and application of the knowledge, attitudes, and skills appropriate to nursing's prescribed roles. (p.9)

\section{Being Compassionate}

The capacity to listen and be compassionate seems on one hand to be natural to me in practice but of course there must have been experiences in my life that provoked me to become who I am. I have looked back over my life to try and understand why the concept of compassion has developed to be so strongly aligned to my clinical practice.

\section{Cultural Background}

Maybe my Catholic upbringing and culture leads to compassion being part of whom and what I am. I would not usually start by identifying my cultural position as being Catholic but I realised that being Catholic provided a structure that gave me confidence when I was younger and this structure enabled me as a professional to be sure of my religious foundation. This religious foundation imbued the structure of my thinking and reflection. It underpinned my ability to develop a coherent spiral process of using reflection to link my inner and outer worlds as a spiritual practise to gain practice insight. Eventually reflexively through recognition of the nature of insight, I was able to appreciate the act of compassion. I realised that the structure of my thinking was already moulded by my religious upbringing to consider that helping others in times of need or illness and also to do no harm to others was the appropriate and right course of action.

When I was younger I was an avid reader and was impressed by reading books on inspiring individuals such as Mother Teresa, Mahatma Ghandi and Albert Schweitzer to name a few. Within their wise words and actions was a sound knowledge of self but an even stronger emphasis on understanding and projecting outwards to other human beings especially those in crisis situations. 


\section{Compassion in Practice}

When trying to examine or explore what it is that elicits compassionate moments in my practice I found it difficult to identify a sequence that was logical. When I observed myself in practice I noticed that there did not seem to be a series of logical steps that could describe the process as step one then step two and so on.

If I describe how I observed myself I would suggest that there is something about the patient and their background that connects with me. It can be a look of sadness or a tear that evokes a compassionate response. Sometimes it is through the swapping of stories that a compassionate response is created; such as the patient and myself both being immigrants, and recognition of both struggling through the intense emotions of being alone and not belonging in the adopted country.

On other occasions I noted that I take a dislike or get irritated by a patient. Through reflection on my practice I have learned however, not to ignore this disharmony. By examining my feelings towards the patient and by actively engaging with compassion I am able to recognise biases and work through them. By doing this I then feel more at ease in looking for cues on how to actively connect with the patient.

Thus some compassionate moments and compassionate listening happen seemingly spontaneously with patients but for other patients I have to make a conscious effort and listen actively before a compassionate response occurs. I am also aware to be on my guard that what is occurring with my patient is not transference.

Over years of practice I have also noticed that there are some patients that I cannot connect to compassionately. It has taken me a long time to realize that it is okay for me not to connect meaningfully with every patient. I relax myself using a mnemonic as a saying to myself such as "This is a natural human response". Possibly on reflection what I realise is that my 'head space' and the patient's 'head space' are not aligned and ready to engage in the same space. The patient may also choose not to engage or their background does not lend itself to 
compassion. They may believe in stoicism and believe that a compassionate response is a weak and vulnerable position to be in.

Compassion implies the capacity to acknowledge another human's suffering or predicament. I believe that to nurse in a compassionate way implies being present for the patient. One cannot practise compassion from a distance. Compassion in nursing implies a close encounter with patients and /or their loved ones. Compassion is the conduit required for caring actions to unfold. A close encounter requires being present.

When I think of being present for someone, the first thing that comes to mind is being in the moment. For this moment in time I will be totally present for the patient. I will actively listen to the patient. I will focus on listening rather than doing. I will clear my mind of its own chatter and biases. I must have an open mind. I will have one focus and that is being present for the patient. I must be available even if that availability entails silence and just being there with the patient. This sequence of activity is supported by Liehr $(1989$,$) who defines true presence as$ "bringing one's humanness to the moment while simultaneously giving self over to the other who is exploring the meaning of the situation for self'(p.8). Presence entails patience. Presence requires a relaxed body posture. What is my facial expression revealing as well as my tone of voice? Presence entails planning so that I make some time to be available and present for these particular patients. This is supported by Johns (2006) who said:

I am very conscious of projecting my presence into the situation, so that the other person can feel my compassion and feel cared for. In other words I intend to touch the person with my caring presence. (p.29)

As I reflect further on my practice and ask some senior colleagues for reflection on my writing and thoughts I will endeavour to capture how I do this. Does it just happen or is there a process involved?

In practice I have noted those patients who for instance look sad or anxious. Those who shed a quick tear or two when they think no one is watching. Those who turn their faces away when asked how they are feeling. Those who seem agitated or angry. These are the ones that often need someone to be there for them and with them. To be present to listen or explain, to 
alleviate or to allay fears or to just be with them in the moment. A fellow human being connecting along the journey of life. A fellow human being in whom they can put their trust.

Liehr (1989) portrays the nurse's presencing beautifully with the following words:

...it is not uncommon for the nurse to feel another's loneliness before the lonely person specifically identifies it. To share another's loneliness is to touch one's own and to stay with it, channelling energies to understand the meaning of the moment for the other. (p.7)

If I am not able to be with a patient immediately I will make a mental note and plan to spend some time with them. Sometimes we work in crisis and in chaos. It all seems too much to keep a focus on what I have observed and plan to return to be with this person. But I have stopped myself and asked myself if this task in the now to attend the physical is more important than the time required for attending to an emotional, psychological, cultural or spiritual need?

Some environments do not encourage the non physical aspects of health or pay lip service to them. In chaotic times I make a point of choosing a patient per shift and make time to be truly present for that patient.

I come back to this phrase in my mind to start the process of reflection where I enter a deeper space. I have pondered the question of how nurses show they care in everyday nursing since my days as a student nurse. I have come to the realization that it is through compassion that I can reach that space unique to our humanity where we are able to identify with another to show that we care. Through compassion I find that I am able to strip off the layers that hide our core human nature. If nurses are being busy with the chores of nursing and coping with resource issues it becomes obvious to patients and their families that there is little emphasis to promote meaningful interactions with them. To work in a community of colleagues means that there is the opportunity to share what I witness when patients are suffering. I need to have the capacity to articulate what has been shared or what I have discerned as I might need to hand over care of a person and their family within the team or go off the shift. 
I know that one of the fears that junior colleagues have when I relate patients' vulnerability is that they will get too close to their patients and feel vulnerable themselves. There is a learning process involved in being able to listen to the expression of being vulnerable. It depends on a culture being established in the health setting in which compassion is valued as a means to reduce suffering and ease the patient's illness journey. Nouwen,et.al (1982) point out that it is almost unnatural for us to be compassionate because we are socialized to be competitive. Because of this "we have lost the simple but difficult gift of being present to each other" (p.19).

Nurses go through stages in learning how to cope with expressions of suffering and the first is acknowledging that they feel uncomfortable being with a person who is suffering. They are not sure what to say or do. They are terrified that they may make a mistake and 'stuff it up' in some way and make things worse. I can recount that many times before I acknowledged that it was sometimes uncomfortable, I would have made some mundane remark and scurried away, unable to know what to do or say when a person expressed themselves. I had to learn that the act of being compassionate when someone is suffering is to be present and keep the conversation simple. Nouwen et al (1983) state that:

We have forgotten that it is often in useless, unpretentious, humble presence to each other that we feel consolation and comfort. Those who offer us comfort and consolation by being and staying with us in moments of illness, mental anguish or spiritual darkness often grow as close to us as those with whom we have spiritual ties. (p.14)

Nurses are in a privileged position to witness many types of suffering and have the opportunity through compassion to alleviate some of that suffering. Nurses might fear that they will be ridiculed by their supervisors if they are identified as spending time communicating with their patients rather than getting their tasks completed. In my experience when writing up patient acuity scores nurses usually indicate scores for activities such as completing dressings, nebulisations, intravenous medication times but very little is written in regard to the time allocated for nurse-patient relationships and the non physical aspects of health. Why is this so? Has the way that care is being delivered managed to such an extent that there is little importance placed on the nurse-patient relationship? 
How then do we show that we care if we are unable to express compassion for our patients? In a recent publication titled "Assessment and Measuring Caring in Nursing and Health Sciences", Watson (2009) presents assessment tools that measure caring.

Compassion requires action. Active listening, a reassuring touch, a knowing glance are a few of these compassionate actions. Compassion cannot take place without feeling for the other. It is being there for another. Compassion leads to healing. Patients remember the interactions and the being there of the nurse more than the many tasks that they undergo. I am not negating the importance of the tasks but I am highlighting the fact that nursing is more than the tasks. Caring requires professional competence and compassion. Compassion and caring in nursing are reflected in the human interactions that take place between nurses and patients.

Buchanan-Barker \& Barker (2004) state "Compassion free nursing is a contradiction in terms" (p.18). The relevance of compassion in nursing is immense.

Compassion does require some self sacrifice. Frankl (as cited in Buchanan-Barker and Barker, 2004) noted "That which gives light must endure burning. The act of lifesaving demands just one single act of heroism." In my experience as a nurse, the burning used as a metaphor for insight indicates that I have stepped from the ordinary space of the ward setting to a different space. This does require stepping out into the unknown and I have to have courage to do this with a person. This is the pathway through which compassion leads to a deep sharing with a fellow human being.

This sharing does not happen with every patient. I have noticed that those who feel most vulnerable in their suffering often share their humanity more deeply. They identify those deep questions that affect all humankind such as: was my life worth anything, am I going to die, what does it feel like to die, what is the meaning of suffering, I am terrified that I may not wake up from surgery? To be present and available to discuss these issues with patients can lead us both and their family if they are present literally to another place than where we began. 
I recognise this new space as a connectedness that is difficult to describe but an experience that opens up a human sharing; it is marked by a special bonding where tears and laughter are shared. It is perhaps where the core of our similarity in being human beings or oneness in humanity is experienced deeply as embodiment. I consider that what marks this embodied experience is the flow of the creative presence or what I term Spirit. During these special times of sharing there is the realization that for a brief time suffering was shared, healing took place and something uniquely meaningful occurred.

This close exploration with another human and that connection through compassion that occurs is an embodied act of nursing. It gives meaning to the practice of nursing and meaningful healing for the patient.

Kabat-Zin (as cited in Liehr \& Smith, 2000, p.14) points out that healing in this sense " does not mean curing but rather the human potential to relate differently to one's life situation so that there is a sense of connection with oneself and others." During this special encounter both nurse and patient reach an embodied knowing. A simple smile, a warmly held hand, a special gesture or an embracing hug shared are all examples of this embodied knowing that I have experienced. In discussion with other nurses it is the memory of those special moments that they hold on to in times of difficulty in order to sustain them. It is these moments that make nursing meaningful. They help to answer the questions of why I am here, and what am I doing or achieving?

However although caring and compassion are acknowledged as being integral to nursing practice, I found when exploring for literature on compassion in nursing, little was written about this focal part of nursing. This observation was validated by Schantz (2007) in her ground breaking research into the concept of compassion when she wrote:

It is noteworthy however, that while caring (or compassion) is identified as nursing's most precious asset, nursing research (or discourse) featuring the professions altruistic ideals is not only scarce, but also lukewarm at best. (p. 49)

A recent publication by Burnell (2009) concurs that this remains the case. 


\section{CHAPTER THREE: METHODOLOGY}

\section{Introduction}

I have always been intrigued by reading theorists and reflecting on their contribution particularly to the shaping of nursing knowledge. I have reflected on how this writing in turn influences my practice. I was always drawn by theorists that promoted the human caring aspect of nursing. This included Travelbee (1971), Watson (1999), Benner and Wrubel (1989), and Roach (1987) who each have been recognised as making significant contributions to using nursing research by naming the process through which nursing becomes visible in practice to the public. I engaged with their ideas and the story of their life and work and have actively incorporated their principles and their wisdom into my practice through reflecting on statements that had particular meaning for me. Their research and philosophical writing often encapsulate personal statements about the interplay of their life, work and practice. I recognise in their writing similarities to the autoethnographic narrative style in which the text reads as though it resembles the writer's spoken word. I will expand further on this comment since this style inspired me and I recognised that I could use this methodology to align my practice writing with own life story.

While the human caring literature (Roach, 1987, 1993; Watson, 1999, 1985) seemed to have something that had informed my practice, I had to admit that there was also something missing. Initially I thought I would find the missing link in wider nursing literature but I could not put my finger on it. I felt that it was more than caring. I could care by being an expert in my practice, but I was trying to identify what it was that enabled me to reach that space with a patient that is special and meaningful both for myself and the patient. I had spent years reflecting on this aspect of nursing practice as it intrigued me. It was not until I read about autoethnography that I realised that there was a method of writing about one's life and practice that was integrative, rather than requiring critique or analysis or conceptual processing. The actual moment in practice was what had occurred and I had experienced it being 'as good as it could be' in that moment. My exploratory questions were: what did I bring to practice and how could I document this successfully? I wanted to step back and engage more deeply with myself 
and to understand how in this process my insight into compassionate listening could create this new position.

I had initially been excited when seeking a method to understand my experiences when I thought phenomenology would be suitable. After being exposed to autoethnography, however, and particularly the writings of Ellis and Bochner (2004), I knew that I had found a methodology that resonated with me and the way I reflected on life and my nursing practice. I could say that my project was informed by these autoethnographers. I have therefore used autoethnography as a methodology to share and reveal through story how compassion moved me from a place of not knowing to a place of knowing what had engendered deep meaning and professional growth in my life and practise.

\section{Defining Autoethnography}

"Autoethnography is a qualitative research method that connects the researcher's personal self to the broader cultural context"' (Foster, McAllister \& O'Brien, 2006, p.44). Autoethnography encapsulates the 'me' in the reflection and the writing. "It situates the individual as a cultural, social and historical being trying to make sense of living and engaging in their world" (Ellis, 2004 , p.34). For me it was a way to make sense and meaning of my practice in the world of nursing. I could consider a range of questions about myself. How do I react? How do I engage? How do I communicate and how do I reflect with regard to patients? I understood autoethnography to be a way of seeing through my eyes, reflecting on this through writing and story, to gain further insight.

Grant (2010) writes that:

Autoethnography emerged as relatively more aligned with the artistic rather than the scientific pole on the science-art continuum, and alternative rather than realist forms of ethnography. (p.112)

According to Ellis (2004) autoethnography is usually written in first-person voice and reveals: concrete action, dialogue, emotion, embodiment, spirituality and selfconsciousness. These features appear as relational and institutional stories 
affected by history and social structure, which themselves are dialectically revealed through actions, feelings, thoughts and language. (p.38)

Ellis points out that some authors "attempt to demonstrate the lived experience and humanity of themselves and their people to outside audiences" (2004, p.38). It is through the use of autoethnography that personal narrative has become recognised as its own genre (p.40).

According to Kidd (2008) the features of autoethnographic include:

- The visibility of a connection between the personal and the cultural, particularly through embodied emotion...

- The display of multiple, partial layers of consciousness within the research text or performance;

- ...layered writing and journals to convey meaning and shared humanity;

- Recognition that action, emotion and language reveal situated meaning, and the opening of a dialogue to debate and negotiate that meaning;

- Research that recognises the audience as possible agents of personal and/or cultural change and aims to motivate the audience to examine their own lives in response to the research in order to bring about that change. (p.36)

In my much more limited experience of autoethnography, I found these principles guided my writing. I wanted to tell my story but I also had an audience to consider. I wanted to express myself but I also had to evolve my conceptual thinking as I undertook this process.

\section{Autoethnography and stories}

When I started my postgraduate journey as a nurse I found it difficult to evolve a way of thinking theoretically. I felt more at home with seeing the patient as an individual with unique needs and a unique way of being in the world. I considered using phenomenology as a means to consider my interest as I was intrigued by the Heideggerian concept of "dasein". Being in the moment, being in the world and experiencing this being in the world. I could see the value of using phenomenology but as a methodology it still felt stiff and constraining to me. I was most interested in the natural story. According to Ellis (as cited in Kidd, 2008), "stories filter through 
all aspects of autoethnographic research as a starting point, as data, as a tool for interpretation and a method of dissemination" (p. 37).

Bruner (2004) argues:

that a life as led is inseparable from a life as told, or more bluntly, a life is not 'how it was' but how it is interpreted and reinterpreted, told and retold. (p.708)

In my experience it is when nurses or patients tell their stories that nurses' attention is grabbed. The description in story evokes and stirs nurses to attention and to sharing their stories. Nurses also reveal the relationships they have had with their patients and relatives through their stories. Reflection on practice appears to be more forthcoming and natural when nurses share their stories. Sandelowski (1994) reminds us of the therapeutic nature in the telling of stories and that "understanding often comes with telling, as opposed to simply having an experience" (p.29). Kiesinger (2002) writes:" ...the stories we tell about our lives often become the frameworks of meaning out of which we act, think, interpret, and relate" (p.107).

Picard (1991) highlights the relationship between story and theory:

In presenting at professional conferences, watch or listen to what happens when one illustrates theory with story. The room gets quieter and people tune into the details of the material. (p.90)

Why? Picard (1991) points out that theory is brought home through story as story reveals our human and relational lives. We are in a caring relationship with our patients but share a common bond through our humanity. Story is also used universally to enhance communication. Grant (2010) states that "autoethnographic storytellers draw people into evocative texts rather than making them feel distanced from what they read" (p.112).

To me it is through stories that nurses explore their humanity and the humanity of their patients. Through story the essence of nursing endeavour is revealed, layer by layer, sheet by sheet, narrative by narrative and poem by poem. We discover that "care is the human mode of being" (Roach, 1984, p.12). 
Through story we are able to delve into that realm of nursing that makes sense of our striving to explore or create meaning for ourselves and our patients. We discover the frailty and vulnerability of human beings but we also discover the incredible strength of the human spirit in the face of what sometimes appears as insurmountable suffering and adversity. As nurses we care about alleviating suffering whether it is physical, psychological, social, emotional or spiritual suffering. It is through compassion that we reach out to fellow human beings in need. It is through compassion that the human need for the alleviation of suffering is recognised and the reason that some respond to the challenge of becoming a nurse. We learn about compassion by writing and sharing stories. According to Foster et al. (2006) through the method of autoethnography:

...understandings of human experiences are informed by interpretative analysis of both common and differing experiences. This research approach seeks to produce knowledge that is drawn from both compassionate understanding and rigorous reflection. (p.46)

Nurses are pragmatic in practice. And this pragmatism could be used in the understanding and application of theory. Doane and Varcoe (2005) point out that theory has to be pragmatic in order for it to have meaning. The question they pose is: "What concrete difference will any idea or theory make in anyone's actual life?" (p.82). I believe that nurses communicate well through the use of story and that theoretical constructs can be explored and developed through nurses sharing their stories.

Benner, Tanner and Chesla (2009) write that: "stories-as opposed to case studies or analytic reports-engage the person in a dialogue of learning with their own historical and personal knowledge" (p.300). Doane and Varcoe (2005) state that a story:

opens space for people/families to inform our knowing and for us nurses to more consciously and intentionally choose and effect our actions to be more compassionately responsive in each moment of nursing practice. (p.89) 
According to Banks (as cited in Sandelowski, 1994)

Human lives echo and re-echo in stories, a feature unique to human existence that demands that nurses listen and hear again. (p.27)

Writing stories has enabled me to make sense of my nursing practice. "Holistic Nursing practice mandates developing expertise in the skills of narrative analysis and (re)construction, skills that help the nurse to capture what is essentially human in health care" (Sandelowski, 1994, p.30). Through writing I am able to make meaning of my world and I am made more aware of the interconnectedness of my world, the patients' world and the worlds of fellow nursing, medical and allied health colleagues.

Sandelowski (1994) points out:

In recent years, nurses have come to (re) value narrative knowing: the knowledge transmitted in the stories that human beings have told each other from the beginning. (p.31)

When I started writing stories involving my evolving practice, I felt uncomfortable at first. It felt self indulgent and not my perception of the rigours of academic expectation. Autoethnography encouraged the use of ' $I$ ' and 'my' which seemed alien as I had always been discouraged from using the 'l' word since being a student as it was considered to be not objective. The collective body of knowledge was promoted and 'l' negated. But I am my practice. Leaving I out denigrated the worth of my own experiences and observations in my nursing practice. Johns (2006) so rightly states about reflective narrative that:

The pathway to authenticity is through genuine dialogue to reveal the true self and to pull away the masks of illusions. He goes further to state: Reflection is an interpretation of what happened given credence through dialogue with self as a form of systematic reflective inquiry and within a wider community of knowing... (p. 60)

How could I write in a way that my story and stories would find congruence and meaning amongst fellow nurses? Nurses have debated our caring roles for decades but seem to be 
dominated by the emphasis of cure rather than care. I wanted through the writing of this thesis to portray that nurses can do both without cure or care dominating our practice. Sandelowski (1994) would appear to support my position as she writes:

There is growing recognition that narratives are a means to achieve what is unique to nursing...the reconciliation of scientific and humanistic imperatives and values in health care...Narrative knowing is a means to know again. Whether nurse or nursed, we are the stories we tell. (p.24)

Bochner (2008) delivered a keynote speech at the 14th Annual Reflective Conference held in Rotorua, New Zealand. In his talk he said that to unfurl knowledge can also mean "to flower, to blossom, amplify, enlarge and expand." Bochner in the same address went on to state: that to be a reflective practitioner one must be willing to examine and reflect on events in one's own practice and to focus on the effects of those events on the findings, thoughts and well being of all those people involved in the events.

By using autoethnography as a method I shared my professional life course and arrived at some conclusions for my practice around the importance of compassionate listening. I hope that this thesis will prompt some nurses to reflect on their own practice and encourage them to defend our caring role through the use of compassion. I know that not all nurses will agree on the importance of compassion and will promote knowledge base as the basis for competence.

Through my stories in my thesis I hope to encourage compassionate competence in nursing where the patient and their significant others become as much a focus of attention as the disease or illness. I put on transitional lenses so that all aspects affecting a patients' health are revealed. I get a fuller more congruent picture by engaging with the whole person. Pollock (2009) writes about this form of seeing and experience: "I was there, I saw, I know...Ocularempiricism confers the authority of the seeing self on the object of sight" (p.636).

By using story I was able to capture what I had seen, reflect on it and make sense of it to inform my practice. Pollock's (2009) words illuminate what I was trying to achieve: "I want to be 
seen so that I can be, so that my subjectivity can be validated and my authority as someone (who sees) authenticated" (p.637).

I hope to encourage my readers to become active and engaged with their patients' stories rather than passive and unengaged. Ellis (1996) points out that autoethnographers do not want their readers to "sit back as spectators but rather they want readers to feel, care and desire" (p.25). These words are so encouraging for me as they immediately conjure up thoughts of compassion. In more recent writing Ellis and Bochner ( as cited in Kidd, \& Finlayson, 2009) remark : "Autoethnography wants the reader ... to empathize and to do something, to act. It needs the researcher to be vulnerable and intimate" (p.3).

Much of nursing practice revolves around suffering and the alleviation of human suffering. Nurses also come into contact with their patients' dying and death experiences. Bochner in conversation with Ellis (1996) discusses how stories are gifts:

....at least to the extent that they make it possible to converse about previously silenced and unspeakable topics and prepare us to appreciate and deal more humanely with the diversity of human experience. (p.25)

When I think of the dying patient in Western Society the discussion around death has been curtailed. It was seen as failure in a scientific world. It was pushed into the background. It was not polite to speak about death and dying. It took hospice pioneers such as Kubler-Ross (1969) and Dame Cicely Saunders (who pioneered the modern hospice movement in England) in the late $20^{\text {th }}$ century to highlight the plight of the dying and encourage discussion on death and dying and intervention with regard to the suffering of the dying.

Elias (1985) also wrote of the 'Loneliness of Dying' in Western Society. He pointed out that death was seen as a natural event in the Middle Ages and earlier centuries but in the more modern societies, the dying are isolated from the living and become lonely and neglected as a result. Ageing is seen as being closer to dying and whereas before the elderly would be part of the family they are now separated from mainstream society and put in aged care facilities. He saw this as a weakness of modern industrialised society. 
In my career as a nurse I have witnessed patients who are dying and their families suffering unnecessarily. This was more evident in the non cancer wards of the hospitals where I have worked. I have witnessed dying patients shunted into side rooms at the end of the ward corridor. They were not neglected purposely but nurses often did not know what to say or how to say what they were feeling. In acute hospital wards dying patients are often no longer seen as an acute priority. However for the dying patient and their family dying and the needs of the dying patient are experienced as being very acute.

As a clinical resource nurse I often came across these patients and their relatives tucked away in their side rooms and feeling abandoned. What had happened to compassion and caring for these poor souls? They needed to be the centre of attention, closer to the nursing station and not placed the furthest away from view and immediate attention. It was by highlighting these patients' predicaments and giving a presentation at the New Zealand Surgical Nurses Conference on the Palliative Patient in the surgical ward that I was drawn to my current role as a Palliative Care Nurse Specialist. I have continued to present at nursing study days on compassion for patients especially the dying. I use story to engage the audience and I have found nurses especially receptive to storytelling. I agree with Ellis (1996) that as a storyteller I want "to transport readers into experiences and make them feel as well as think" (p.19).

Benner, Tanner and Chesla (2009) point out that unavoidable suffering is often made worse because we have forgotten or do not engage and "we avoid our sense of finitude by technological promises of continuous progress and technical solutions" (p.297). These are inadequate means to convey the reality that is to be confronted.

Benner et al. (2009) highlight the importance of narratives as:

The narratives are moments where language, touch, rituals, intimacy, presencing and courage, and new understandings and possibilities are experienced. (p.297) 


\section{Designing an Autoethnographic Project}

Bochner (1996) states that:

Ethnography should broaden our horizons, awaken our capacity to care about people different from us, help us to know how to converse with them, feel connected. (p.26)

This is very exciting for me as that is what I want nurses to be able to do for the suffering and the dying. To listen, engage and connect.

These statements by the pioneers of autoethnography encouraged me to write in my own style and to share my stories to enable me to reflect on them and invite others to read and reflect about them as well. As Bochner (1996) highlights: "One of the uses of autoethnography is to allow another person's world of experience to inspire critical reflection on your own" (p.22).

Autoethnography became a natural fit to my writing as a vehicle describing my engagement and encounters with patients and other nurses. I have endeavoured to describe how compassion has focused my practice and has become incorporated with my being a nurse.

Ellis (2009) describes that as an autoethnographer she is:

both the author and focus of the story, the one who tells and the one who experiences, the observer and the observed, the creator and the created. I am the person at the intersection of the cultural, thinking and observing as an ethnographer and writing and describing as a storyteller. (p.13)

But is autoethnography accepted as rigorous research? It has been criticised as sometimes leading to "narcissism, self-absorption, exaggeration and self-indulgence" (Foster, McAllister, \& O'Brien, 2006, p.48). Autoethnography may not be as generalizable in the mode of traditional research methods, for example by choosing random respondents and surveying them. However, as Ellis (2004) points out:

readers...determine if a story speaks to them about their experience or about the lives of others they know. Readers provide theoretical validation by 
comparing their lives to ours, by thinking about how our lives are similar or different and the reasons why. (p.195)

This is also the view of Foster, McAllister and O'Brien (2006) who say that one of the "foremost benefits" of autoethnography is that it "allows another person's experiences of and in the world to inspire the reader to reflect on their own experiences, so that these may be recontextualized" (p.48).

The aim and advantage of autoethnography is the way it can enable the researcher to connect "both as writer and subject with the reader via an autobiographical account". The reader can then 'engage with events' in the researcher's professional life and with the researcher 'as a person' (Humphreys, 2005, p.842). Writing enables the researcher to understand the 'self'; "the very act of writing becomes a way of being and knowing" (Foster, McAllister, \& O'Brien, 2006, p.49).

Ellis (2009) in her most recent book claims that "autoethnography offers the potential to expand scholarship about human experience" (p.16). Is nursing not concerned with researching the illness and suffering experiences of our patients and their loved ones and then using this information to plan and/or assess our nursing care?

On the question of validity in autoethnography, Ellis and Bochner(2000) point out that validity "seeks verisimilitude; it evokes in readers a feeling that the experience described is lifelike, believable, and possible (p.751)."

With regard to reliability in autoethnography, they state:

Since we always create out personal narrative from a situated location, trying to make our present, imagined future and remembered past cohere, there is no such thing as orthodox reliability in autoethnographical research. However, we can do reliability checks. When other people are involved, you might take your work back to them and give them a chance to comment, add materials, change their minds, and offer their interpretations. (p. 751) 
Johns $(1998,2000,2002,2006)$ a leading force in promoting reflective practice writes:

Narrative resonates with chaos theory in the sense that clinical practice is deeply complex in its wholeness and yet within that apparent chaos there is order or pattern recognition. Narrative is movement; like a stream gathering pace rhythm, deepening, widening, being shaped by the landscape as it flows towards the sea. I can tune into and flow with the inherent order rather than resist the flow of energy by forcing ideas into boxes. This was a vital understanding in constructing narrative. (p.58)

As we live in a multi-cultural society in Aotearoa New Zealand, it is important to note how culture informs lived experience. According to Kleineman (as cited in Ellis, 2009), autoethnographic stories:

can help us understand how culture informs practice... we will not know if others' intimate experiences are similar or different until we offer our own stories and pay attention to how others respond, just as we do in everyday life. (p.143)

Do Maori respond in a similar way to Western based nursing care or can we inform our practice by listening to Maori nurses and patient experiences of nursing care?

According to Richardson (as cited in Keats, 2009) "narratives are able to act as a means of knowing and a method of telling" (p.181). Keats (2009) also points out that: narrative research...can serve in gaining a richer and more complex understanding of participants' experiences and generating new perspectives and knowledge. (p.182)

Ellis highlights the fact that when doing research with intimate others there are no set rules to follow. Ellis (2009) cites the writing of Frank (2004) to illustrate this point: We do not act on principles that hold for all times. We act as best we can at a particular time, guided by certain stories that speak to that time, and other people's dialogic affirmation that we have chosen the right stories....The best 
any of us can do is to tell one another our stories of how we have made choices and set priorities. By remaining open to other people's responses to our moral maturity and emotional honesty.... we engage in the unfinalised dialogue of seeking the good. (p.309)

In this thesis I write and reflect on my nursing stories. These are similar to the "narrative vignettes" or "performance vignettes" presented by Humphreys (2005) in his own autoethnography (p.842). My stories can be found in Chapter 4. I then lead readers through some of my own journey so that they can form a picture of situatedness of my stories within my cultural and social background. I then go back to the stories in Chapter 6 by stepping back from the text and analysing further for any other themes revealed.

\section{Creating the Stories}

The stories were initially written in note form on a computer when these events were occurring in my life. I used a process of reflecting on the actual note form of the story as text. This process was similar to the first two of three steps in the method described by Smith (1999) for self-ethnography: diaries, free writing and "spontaneous notes", and "self-introspection" (p.267). I was very aware of how the images of the events and the text were constructed, especially in relation to my views on the culture of the context and my own culture.

The stories are narratives of practice drawn from nursing a range of patients over 30 years. In selecting the stories to use in this research, I considered the experiences I had had with patients and colleagues that had taught me the most about compassion and listening. I drew on these practice examples, creating stories that represented situations that had taught me much about myself as a nurse. Seven stories focus on patients and one on a colleague. Part of normal palliative care practice is for colleagues to share stories about practice, in order to reflect, learn and advance their practice. I gave earlier versions of these stories to senior nursing colleagues and asked them to give me feedback on my practice. They were generous in the attention they gave them and the written feedback they provided. This extended my own reflection and learning. This process was similar to the third and final step in Smith's (1999) 
process of self-ethnography: "interactive introspection" or discussing a story or experience with someone who can bring an understanding to it (p.267).

\section{Ethical Considerations}

Ethical approval for using fictionalised practice stories was granted by the Human Ethics Committee of Victoria University of Wellington. Foster, McAllister and O'Brien (2006) warn that in autoethnography the researcher needs to be particularly sensitive to issues of consent and anonymity. Although the researcher needs to think carefully about whether others should be included in a narrative, it can help "evoke understanding of the story and the social issue(s) it addresses" (p.48). I was unable to seek permission from patients or families to use their specific stories in this research. Some patients had died and approaching their relatives could have been too distressing for them. As I was also drawing on practice across a long period of time, some patients' and relatives' contact details were no longer available to me. I have therefore fictionalised stories, using pseudonyms and changing details such as place, age and sometimes gender, as well as specific conditions and treatments. Morse (2002) cautions whether we can ever assure anonymity, or can change names and characteristics and still maintain a story's validity. These stories still retain, however, the aspects of practice that illustrate what happened in encounters with patients and colleagues and what I learned about compassionate listening.

For the story that centres on a colleague, I gained approval from the Human Ethics Committee to ask her for permission to include the story in this research. I approached her in person and gave her a letter of invitation and a consent form. I also gave her the story to read and offered to change any details that she did not feel comfortable with or that she felt might identify her. She did not request any changes and gave me permission to use the story as written.

I also gained approval from the Human Ethics Committee to approach the five colleagues who had given me feedback on my practice, for permission to use their feedback and to quote from it in this research. Each colleague was approached individually with a letter of invitation and a consent form. They were also given the quotations I wanted to use in this thesis. Each colleague gave me permission to do so. 


\section{Summary}

I had reached a point where, although there are no set rules for conducting research with intimate others, I had framed this project around reflecting on practice narratives through my own life story. However, I was very aware that my reflections could easily be preconceived and biased. I had to guard against this type of contamination and write the narratives as closely to reality as I could. I knew that the narratives I would be writing were my interpretation of events and my reality of my recollections. "Autoethnography asks that I enter into the experience of another as much as I think about the experience of self" (Ellis, 2008). Ellis (2009) goes further to say that it is her and Art Bochner her partner's: "desire that emotional autoethnographic narratives that offer compassion and empathy in our responses to suffering will make human sciences more human and produce scholarship that heps us figure out how we should live" (p.151).

By writing the stories I would be looking at my connectivity with those human beings I was writing about. My sources of data would be my writing and my reflection on the stories. According to Levine (2006), "Qualitative research has been described as that which facilitates and creates understanding of the dynamic flow of lived lives" (p.55). Autoethnography would fall in the realm of qualitative research as what I was trying to explore or reveal through reflection would not be suitable using quantitative research methods. According to Leininger (as cited in Levine, 2006), "qualitative research is extremely useful in order to understand what is 'going on', and the results increase the body of qualitative knowledge" (p.55).

In this chapter I have outlined my rationale for choosing to conduct an autoethnographic and reflective project. Johns (2006) sums up how his practice is enriched by narrative and reflection in the following statement:

Due to its reflexive nature, the narrative might seem repetitive; yet a new twist is always present for the discerning reader. Reflection helps me to reveal the complexity and uncertainty of easing suffering for people who are dying and their families, pulling out for deeper reflection on significant issues... (p.59)

In the following chapter I will introduce the reader to the first four stories and my initial reflections on them. 


\section{CHAPTER FOUR: PRACTICE NARRATIVES}

\section{Introduction}

In this chapter, four fictionalised stories are presented and each text is followed by a reflection. These documents sit within the autoethnography and are encountered before my own life story text in Chapter Five, reflecting the sequence that I engaged in during the project. Earlier versions were written as practice exemplars, initially within my advanced practice role and shared with colleagues as peers in this role. I reveal how I am as a nurse, how I process my work world through reflection. The reason I chose these particular stories was that I remembered how they had led to me actively reflect on my practice. They are stories that could resonate with nurses no matter which specific area they worked in. They reveal how I considered compassionate listening as one focus in my practice.

The four stories in this chapter have been presented so as to protect the identity of the people involved. Names and details in the stories have been altered.

\section{High Anxiety}

Bob was suffering from cancer. He had tried one course of chemotherapy and decided against continuing the chemo regime prescribed for him. Bob often reminded me that chemo was very toxic for the body and was derived from mustard gas used in trench warfare during the First World War. He was very anti western medicine at this stage of his disease progression and distrustful of the medical world. He believed strongly that the large drug companies were in a conspiracy with doctors to control people's health, to poison them when necessary and to control them with mind-altering substances such as anti-depressants.

I could have let this ride over my head but Bob truly believed his conspiracy theory and nobody could persuade him otherwise. At first I had found it difficult to deal with Bob as he was quite controlling of his environment. For example, on one occasion he told me not to poison my body with sugar and to drink Stevia instead, insisting I try it. My cup of tea was duly sweetened with Stevia and I almost gagged drinking it. On my next visit, Bob asked if I was using the Stevia 
and I said "no". "Why not", he retorted gruffly. "Because it tastes like crap," I replied. He then gave me copious information that he had downloaded from the Internet to convince me further. I spent an uncomfortable session with Bob, who kept trying to change my bad sugar habit. He advocated alternative options about almost everything advocated by western medicine. No low fat margarine for him but heavy virgin coconut butter that he imported from Fiji. He promoted full fat butter and full fat non- homogenised milk.

While chatting to Bob, I noticed that he broke out into sweats for no apparent reason. He was apyrexial. He also did not sit for long. He wanted to be up and about, driving around to organic shops and health stores where he would chat or argue for hours. I tagged along and chatted to him in general without letting him know exactly what I really thought of his ramblings. I felt that this was his time and that he should enjoy it. I was just a bystander providing his wife Anne with a few hours of respite. He had been diagnosed 20 months prior to my first meeting him and had already outlived the oncologist's prognosis by months. I felt sure that a lot of the potions and nutrients plus a healthy dose of stubbornness on Bob's part extended his predicted lifespan. But this gain in life time was not without its financial and social costs.

His daughter had come to be with her dad but his interference in what she ate or tried to eat caused so many arguments that she left to return overseas. Poor Anne was nearly at the end of her tether as well and they slept in separate rooms. As I put all these events together I felt that he was suffering from anxiety, not only because of his impending death but because of his obsessions with eating, looking for alternative medicine and worrying that politicians, the drug companies and doctors were in a conspiracy to control people. Although he had told me that he did not believe in God or the afterlife, some of his observations and questions hinted that he may have been anxious about the afterlife. He got thirsty and drank lots of purified water bought from an alternative "vibration" therapist that he saw once or twice a week. As I spent time with him I realised that this sleepiness was because he spent most nights on the internet checking alternative remedies such as using a synchrometer and an electrical cancer cell zapper device. His wife Anne had even had night lights installed in the passages so that he would not walk into things in the middle of the night as he was pacing about excited by another internet find. He also did e-mail ordering at night for a myriad of alternative potions between 
using the cancer cell zapper. For example he had read that parasites exacerbate cancer and was drinking Black Walnut tincture and giving himself coffee enemas to clean his "poisoned system". The next week he was eating matchbox sized portions of raw liver which he believed assisted in killing the cancer. It was difficult for me to understand his rationale at times. It was nauseating watching him munch on slightly sautéed liver. He said that the raw liver tasted a lot better than a lot of the herbal stuff he had taken and was still taking.

His life was a vicious circle. Anxiety about dying, about breathing difficulties near the end, losing his mind, his conspiracy theories, and obsession with alternative medicine was exacerbated by insomnia and his internet browsing. I tried to suggest something light to sleep would be of benefit to him and he would feel better if he slept at night. I tried to explain to him that lack of sleep was doing more harm than all the things he was taking. He listened with some interest but would not see his general practitioner to prescribe something light to help him sleep. Then "they would control his mind again" he countered.

His disease progressed as did his insomnia, anxiety and he started to become very paranoid. He thought that his wife and mother in law were going to kill him. They were linked with the doctors and once he got to hospital it would be the end of him. He also had gross lymphoedema of his lower limbs exacerbated by his lack of sleep and his disease progression. He asked me to massage his lower limbs. This was a big request. I was used to putting a hand on a shoulder to reassure or to hold or shake a hand now and then but to massage another male's legs was not something I was used to doing. However I felt that I could not refuse his request. I was soon on my knees slowly massaging his bloated skin. It felt very unnatural for me. After a while I forgot about my ego and reservations and could feel and see Bob relaxing as I slowly massaged his feet and calves trying to push and will the heavy fluid away. There was a connectedness that I had not experienced before with previous patients. It was something special, unique and as close to something that I can only imagine as being spiritual. I began to feel humbled by this new experience. Bob had allowed me through parts of his mind and now had invited me to touch his body. This was an amazing act of trust in me. This trust breakthrough led to Bob sharing his thoughts about the afterlife, whether I thought his life had had any meaning. How could he now try to believe when he had spent his life saying he was a 
professional and could not believe what could not be seen or proven? He told me of his fear of losing control of his bladder and bowels but especially his mind as "they would then be able to do things to him without his permission".

It became too difficult for Anne to cope at home so Bob was transferred to a room at an aged care facility. His breathing was deteriorating and he became anxious about asphyxiating. $\mathrm{He}$ was still not sleeping and had been stopped from driving. He still seemed paranoid at times. I then thought of using Morphine to help settle his laboured breathing. I suggested that he should try Morphine syrup in small quantities at night to assist his breathing. I convinced him that his anxiety was exacerbated by insomnia. As he had been an avid reader I reminded him how intelligence agents got information or confessions-by depriving their captives from sleep. I thought to myself that the Morphine would probably help him to sleep as well.

Within a week of nightly morphine, Bob was a changed person. He was sleeping for four to eight hours intermittently at night and had naps in between. He became interested in his family again. He asked again how he could be accepted by God in the afterlife when he had not lived a good life. I thought of the parable told by Jesus where the owner of a field pays all workers one Denarius whether they worked all day or the last hour. In other words God's justice is not human justice. He became less paranoid, less obsessed and less anxious. He wanted Anne around more and no longer thought she was out to get him. He was able to make peace with the world and confided in me that he had made peace with God as well. He no longer feared dying or death. Bob passed on peacefully ten days later with his family around him. Although I was not able to assist Bob in the conventional sense, initially by suggesting sedatives or anxiolytics and asking a physician to prescribe something I was able to reach him on another level. Through compassion and listening I was able to reach in and touch Bob's unique humanity so that there was something in my humanity that allowed him to express his fears and feeling without feeling threatened in any way. For those times we were able to be in the world together as unique beings but also by embracing our sometimes frail humanness.

So by being aware of my compassionate self and by listening and trying not to be judgemental I was able to gain Bob's trust and he agreed to taking Morphine, which assisted by easing his 
laboured breathing, helping Bob to relax and sleep. This reduced his overall anxiety and improved his quality of life, even if only for a few weeks before he passed over.

Learning the art of listening has taken many years of nursing. We are so busy doing, directing, talking, examining, teaching, curing and trying to care that the importance of listening seems to somehow get lost.

How can we expect our patients and ourselves to find meaning in a situation without active listening taking place? How can we explore together with our patients feelings and emotions, their deep questions of what may seem to have become a cold, grey, painful and meaningless world and the seemingly "hopelessness of imminent death" (Frankl, 1959, p.39) by not having the time or making time to listen to them?

In years gone by I would have spent my hours with Bob trying to convince him that his thinking was wrong. That he was wasting his time and money on unproven and untested alternatives. I would have been too busy telling him things and would not have listened much. Possibly a bit of selective listening, filtering out the bits that I wanted to challenge or argue about, but not really hearing Bob's concerns. Years of nursing have enlightened me to the importance of listening with compassion. Through listening and sometimes taking in the uncomfortable silence that occurs on occasion, I was able to realise that much of Bob's anxiety was based on finding some meaning for his life.

Without listening would I have gained insight into these aspects of Bob's palliative journey? If I had spent my time trying to push the western medical model would I have not in some way have destroyed Bob's zeal, Bob's hope? I feel that by listening compassionately I was able to recognise Bob's anxiety and to relieve it in some way. Nietzsche (as cited in Frankl, 2004) once said that "the man who has why for his existence, will be able to bear almost any how" (p.9).

Frankl (2004) questions the meaning of suffering and the uniqueness of each individual and situation. Frankl (2004) concludes that: 
when a man finds that it is his destiny to suffer, he will have to accept his

suffering as his task; his single and unique task. He will have to acknowledge the fact that even in suffering he is unique and alone in the universe...no one can suffer in his place. His unique opportunity lies in the way in which he bears his burden. (p.86)

I could try to lighten Bob's burden in some way with my nursing experience and skills and by sharing my humanness with him. How Bob bore his suffering was his choice, not mine and not anybody else's either. This is supported by Husted and Husted (1995) who state "the more control a person has over his or her life, the more it is a human life and the more it is his or her own" (p.205).

According to Chochinov (2006), those practising in palliative care are better equipped to deal with end-of-life symptom distress but what remains less developed:

is the knowledge base and skill set necessary to recognize, assess and compassionately address the psychosocial, existential and spiritual aspects of the patients dying experience. ( $p .84$ )

Kubler-Ross (1995) wrote about the importance of actively listening to patients. Not only should we actively listen but health professionals should look for and recognise symbolic, nonverbal language which is evident in dying patients. Some responses, according to KublerRoss, do not come "from the intellectual quadrant but from the intuitive, spiritual quadrant" (p.29).

I feel that because much of our socialisation in nursing and palliative nursing is based on the intellectual western model of health care, we battle to come to grips with the emotional, psychological and spiritual aspects of life as separate entities but this is in fact not how life is lived. This integrity of life and personality becomes even more important during the end of life journey. If we are to accompany our patients we have to learn to listen more and be prepared to engage more or to just be present. This is an area that I believe needs to be explored more as it relates to that part of caring that has traditionally been part of nursing and which is 
threatened in the managed care and bed management environment that we are presently faced with. I have noted that nurses are so used to educating, instructing, and doing a myriad of nursing tasks that they often forget to listen or listen without really paying attention to the patient.

\section{To Be or Not to Be.....}

My pager rattled and screeched in my pocket. It indicated a 777 emergency cardiac arrest call. I rushed up to the ward to assist. The patient, a middle aged woman had stopped breathing and had also gone into cardiac arrest. The cause of her cessation of breathing was evident from the yellowish brown fluid which flowed out of the side of her mouth. Pass me the suction was my first request. The patient had obviously aspirated. She had a nasogastric (NG) tube in place but had vomited past the tube. Within seconds I had sucked up two hundred millilitres from her mouth and throat. I attached the suction to the NG tube and drained another four hundred millilitres from her stomach.

I ascertained that the patient's name was Maggie. By this time the crash team had arrived and cardio pulmonary resuscitation was in full swing. I assisted the intensivist registrar with the intubation. Again we sucked up more vomitus fluid from the endotracheal tube. The smell was especially sharp; bile and faecal matter were not a good mixture. I could feel myself salivating more and more and almost gagging. If the smell was having this reaction on me then how awful it must have tasted in the patient's mouth before she passed out after aspirating the same fluid into her lungs.

After what felt like a long time but was only about five or six minutes in reality, we felt and found a femoral pulse which indicated that she had a cardiac output. Cardiac compressions were stopped but we still had to continue assisting her breathing with oxygenation and an ambubag breath now and again.

The intensivist registrar asked for Maggie's history. The ward nurses were not all that sure except that she had had a laparotomy the day before. The patient notes arrived and to our dismay it was noted that the registrar had spoken to Maggie that afternoon. The laparotomy 
had revealed extensive secondary cancer growth, so extensive that the surgeons were unable to remove the cancer. Maggie had decided that she did not want chemotherapy but would consider palliative radiation and terminal care. She wanted to get home as soon as she could to be with her family and attend to what Kubler-Ross (1997) refers to as "unfinished business". She had also requested a Not for Resuscitation status. The form had been filled in and signed by the registrar and was in the front section of the patient's notes.

The arguments started flowing between the surgical nurses, the doctors and the crash team staff. What now? How inappropriate was this? That there was tension in the air is an understatement.

Whilst the arguments and counter arguments were flowing I just held Maggie's hand and said a silent prayer for her that she might be at peace. I noted her eyelids flutter and then her eyes opened. I have seen the odd horror movie or two but the look of absolute terror in Maggie's eyes was indescribable. I reassured her and told her to relax and just breathe slowly and steadily. She looked at me pleadingly while squeezing my hand. I looked into her gaze and asked her if she would like us to continue or if she would like us to take the tube out? The look of terror in her eyes was replaced by a look of relief. She nodded that she would like the tube removed.

I asked the intensivist registrar if he had witnessed her request and he nodded in the affirmative and removed the tube. I spent some time with the nurses cleaning Maggie up. Her husband was on his way but lived a few hours drive away from the hospital. Maggie just wanted to spend some time with him. She wanted to stay alive until she could say farewell to her life partner of many years.

We had a quick debrief session in the nurses' office. I pointed out the importance of the doctors informing staff if they write up things like a Not For Resuscitation order. I also pointed out that the nurses should have a brief look over the last day's entries in the notes during or just after handover on each shift so that they know what is happening to their patients. This would help in preventing a reccurrence of what we had just witnessed unnecessary medical 
intervention and a prolongation of Maggie's suffering. It is our duty as nurses to know whether our patients are "to be" resuscitated or "not to be" resuscitated. I went home soon thereafter and reflected on the evening's events.

I found out the next day that Maggie had spent four hours with her beloved before passing on peacefully.

On further reflection I have come to the realization that my years of practice and actively listening with compassion have enabled me to be present for patients such as Maggie. It is so easy for a nurse to be so caught up in the immediacy and frenzy of the moment that subtle cues such as the patient's facial expression and the story behind the eyes are missed.

Each patient's story enriches my nursing practice. Each death enables me a glimpse at the frailty of human life and also the richness of the sharing of humanity and spirit with the patient and their relatives and fellow nurses and health professionals. We as nurses must cherish that privilege that we have of closeness to our patients in their suffering and strive to retain compassionate listening as part of what we are and what we do.

I have used the term compassionate listening to reinforce that which is part and parcel of nursing practice. If we just listen we may forget or not really hear what the patient is trying to share with us. If we listen with compassion this presupposes that we are trying to place ourselves in our patient's shoes, to share something of our common humanity and frailty in a time of suffering or uncertainty. Compassionate listening creates a spirit of awareness in us as nurses of the emotional, psychological, social and spiritual needs of our patients' that should be addressed if true healing and health is to be realised. In the dying patient, compassionate listening can give the patient some comfort in the fact that they are being heard and they are not alone in this last passage of human life. 


\section{The Arrest}

I was called to assist with a cardiac arrest situation where a woman in her twilight years had suddenly collapsed. After thirty four minutes of cardio-pulmonary-resuscitation (CPR) all involved with the CPR agreed that to continue would be futile and in vain.

June, the patient's primary nurse, had said to us that her patient had been recovering from surgery and had been chatting to her in a jovial fashion just minutes before. June looked forlorn and anxious about what had just occurred and when I asked her if she was okay, tears welled up in her eyes and she turned away and mumbled she was okay and continued tidying up. I asked June if this had been her first witnessed arrest and she nodded with tears welling up in her eyes once again. June said that she had better get another job because this was not what she had envisaged or expected.

I thought back to the arrests and deaths that I had witnessed over the years and how each impacted differently. Some experiences have impacted my very being and have stayed with me forever and others became part of the mundane every day experiences of my nursing life that are soon relegated to become a forgotten memory.

I could see that June was very distraught and I had witnessed her nursing and interaction with staff and patients before. She was very compassionate and caring and I did not want this episode to destroy her confidence or have a negative impact on her. I decided to accompany her through the process of caring for her deceased patient and the process of communicating with the police as this would be a coroner's case. I asked June if she would like to assist with tidying up the body which was in quite a messy state as the deceased had vomited coffee ground type stomach contents all over her face and bedclothes. We would be cleaning her up but leaving all tubes, catheters and intravenous cannulae in situ. June said she would like to be with us.

I watched June as she cleaned up the vomitus from her deceased patient's face. June was gentle and spoke to her lovingly as if she was still alive. June continued to tidy the woman's hair, just combing it gently and looking at her with kindness and compassion. 
I reflected that if June had not assisted with tidying up the body all she would have remembered was the actual arrest and resuscitation scenario. Here I was witnessing that part of the art of nursing which is often forgotten. June, although an emotional wreck herself, had managed to care for her patient and show the utmost respect and compassion in doing so. She had sacrificed her immediate feelings of wanting to flee the scenario but had continued to nurse the deceased in a dignified and compassionate manner.

There was more to come. I explained to June that as she was the primary nurse the police would soon arrive to interview her. I said she had nothing to fear and feel guilty about and that she should just tell them the facts as they occurred.

The police arrived and I offered the three police officers' chairs. The two tall males declined the offer but I insisted that they sit. I asked them, "How would you like to be June's size and be interviewed by two big fellows like you? Would you not feel intimidated?" They agreed and sat down. I stayed with June through the police interview which ended uneventfully.

With this the family arrived and the deceased patient's daughter just wailed and wailed. June stood in the doorway of the single room and I could see from behind that she was sobbing too. I stood behind her and placed a hand on her shoulder reassuring her that it was okay to cry, there was no shame in it, and that it revealed that she cared for her patients. June stayed with the relatives and shared with them what had happened and the conversation she had with their mom just prior to her collapse.

When the relatives had left and the police had escorted the body out of the ward I sat down in the office with June and the other ward nurses and had an informal debriefing with them. June said she had felt guilty and that she was useless as she felt that she had gone to pieces. I reassured her that her tears had been because she cared. I told her that through being compassionate she had connected with the patient. I also said that she was a good nurse and reminded her that she had already helped many patients with her ability to care and connect. I 
have since seen June and she said that she will always remember that night and that she had learned a lot as well.

On reflection I was reminded of Benner's (1984) research describing the transition from Novice to Expert and how things just fall into place for the experienced nurse and how the same scenario can seem overwhelming for the novice. It also reminded me that many experienced nurses can also be novice nurses when it comes to the dying patient. Many have practised for many years yet have never witnessed a full blown arrest, resuscitation attempt and the patient dying.

Why did I recognize June's humanity in this crisis situation? I could have left her to her own devices and let her just get on with it and get over it so to speak. Years of nursing practice have alerted me however, not only to my patients' humanness but to my colleagues' humanness as well. Listening for the cues of distress or angst in others requires compassion so that one can tune into being human in the moment.

\section{Trust}

I was asked to attend a meeting to discuss options for Aroha as she had been non compliant in attending her palliative radiotherapy sessions. She would either miss them or turn up hours late. At this stage Aroha was an inpatient. Aroha was suffering from advanced cancer and there were no further medical treatment options for her other than palliative care.

I entered her room where the meeting was being held and introduced myself as Peter a palliative care specialist nurse. The whole collaborative team were present as well as a Maori advocate and some family support. Aroha appeared impoverished to me. She was a large woman with a well worn pair of track suit pants and a frayed tee-shirt. The social worker present had found that the home situation was not optimal for Aroha's worsening health. She lived in a rural area with no electricity and no running hot water.

Aroha was asked why she had not attended and she started to give us a glimpse of her present life. Her teenage daughter was writing final school exams and was her main caregiver. 
She had gone to sort out some things at home. Aroha described how she had felt boxed in and experienced bad things present in the hospital especially after the 'burn'. The 'burn' was Aroha's term for radiotherapy. She described further how she felt oppressed by the building and hospital surroundings. They were pushing down her spirit. She told her story through bouts of tears and sobbing. As she described her situation I could feel myself warming to this woman who was describing how what was normality in our lives was definitely not normality in hers. It was not long before I felt my own eyelids moisten as she continued telling us her of her life journey over the past week or so. She had just needed to get out of the stifling and threatening atmosphere of the ward so that she could engage with nature and also to sort out a few private things.

It was difficult for her to understand that the radiotherapy department ran a tight schedule and half an hour to an hour waiting for her to arrive meant that others could have been treated and that there was already a long waiting list for radiotherapy.

We discussed the most suitable options for Aroha to be accommodated during her next two weeks of radiotherapy. She was unable to stay with whanau in Hamilton due to their own impoverished circumstances. The best option was to stay at the hospital accommodation but Aroha had no money to pay for the accommodation. I pointed out that the hospital could possibly pay for Aroha as her staying as an in-patient would cost the hospital a lot more and there was already a shortage of in-patient beds. The ward management agreed and paid for her stay out of their budget. On Aroha's last day of radiotherapy I was to reconnect with her and discuss with her what the Palliative Care team was all about and how we would be team looking after her from now on.

I went up to the radiotherapy department to meet up with her in case she got lost on the way to our department. She was late in arriving but the radiotherapy team said that she had thought yesterday had been her last treatment. They showed me a beautiful posy of flowers and greenery that she had presented them with. Aroha had hand picked flowers and greenery by walking around the hospital gardens and had spent time and effort to show appreciation to the radiotherapy team. 
I met Aroha and her daughter and we sat chatting at first. She said that she was glad that she it was her last "burn" as she felt pretty tired. She wanted to know what I was there for and what I had to offer. I explained our role of accompanying her on this last human journey that she was travelling and that we were a phone call away. We would also manage her symptoms such as pain and nausea and breathlessness if and when they occurred. I also said we would just be there for her. She again asked what I was able to do for her. I said mainly to just be here for you when you need me, when you have questions that need answering. We sat for a while in silence. Aroha's daughter had left the room and was looking through some magazines in the passage. I just sat and opened my mind to her not saying anything for once. I began to feel truly present for her and said a quiet prayer for her. She told me that she was visiting Maori elders for old herbal remedies and if that was okay. I said no problem. If they made her feel better or stronger than there was no issue.

We sat in silence again for a while. It was a peaceful unhurried silence and not uncomfortable as some silences are. We were just able to be in each other's presence. A few tears ran down her cheeks and she waved me away as I motioned towards her. We spent some time just being two human souls acknowledging our frailty and existence. Aroha then got up and said: "thank you so you be the main man now" and embraced. In the silence we had connected, something special happened and trust was born in our relationship of nurse and patient. I knew that I had come a long way.

\section{Summary}

In this chapter I have related a series of practice narratives. Each story has significant insights that evolved in the context of caring and enabled me to engage with the person and their family. In the following chapter I relate aspects of my own life journey and reveal insights gained in writing using the autoethnographic method. 


\section{CHAPTER FIVE: TRANSITIONS IN A NURSE'S LIFE STORY}

\section{Introduction}

In this chapter I document aspects of my life journey using the autoethnographic method. I used the 'I' voice and layer my thoughts and memories of these events. I include events when looking back over my life to try and understand why the concept of compassion has developed to be so strongly aligned to my clinical practice. Two further stories are embedded within my own.

To write this chapter I began by asking myself how did I reach where I am now? There were moments in time that had a bearing on my life's journey. These were the moments that brought about change in my life course (Elder, 1999).

\section{My Story...}

After completing my schooling I underwent compulsory national military service which was the norm in South Africa before 1991. I was drafted to the medical corps and did my training as an operational medic which entailed active service on the Namibian and Angolan borders. I was at this stage pondering what I should choose as a career. I had registered to do social sciences at university but had pulled out to get my military service out of the way.

I spent some time assisting at mission stations between providing medical cover for the military base I was stationed at. Working with patients stirred something within me. I witnessed how nurses could change have a positive influence on people's lives and this fitted in with my life's ambition which was to care for others in some way. This wanting to make a difference and service to others stemmed from my Catholic upbringing. By the time I had completed my national military service I had applied and been accepted to commence my general nursing training.

My nursing training was exhilarating but a busy time. This was not an easy transition in my life as there were many in nursing at the time that did not make the life of a male nursing student an easy one. Some were the older vocational spinster type nurses that were not used to 
working with male nurses and there were the feminists who were not endeared to males encroaching on their turf. They tried everything to make my life as a student difficult. One of my first assessments for example was to teach a sixty five year old spinster how to self catheterise using a mirror. I perceived that to be mean. Luckily the patient and I got on well and I was more embarrassed than she was. She had been a teacher and had a great sense of humour. She remarked that we would learn something together. Looking back I realise now that antagonism towards me as a male nursing student by some registered nurses strengthened my resolve to be a good nurse. During this time as a student I came across the writing of Elisabeth Kubler-Ross(1969) and Viktor Frankl (1959) which also planted seeds in my brain. Dying patients should not be abandoned and that life should have meaning. In nursing college I had learned that health included physical, psychological, emotional and spiritual aspects. In practice however, the physical took priority. The medical model promoted the physical.

Once I had qualified as a registered nurse I did not ponder the holistic model of care too much. I was too busy gaining new knowledge and concentrating on not making any mistakes. Soon after I left for the mines and spent the next six years nursing mainly trauma patients. The mines offered triple the salary plus a house and I was soon to be married to Wendy.

During this time I witnessed the Kinross Disaster where an underground fire caused the loss of life of one hundred and seventy seven people. It was a heart breaking and gut wrenching experience to try and identify the bodies. Some were badly burnt and some did not have a mark on them. I experienced the cruelty of racism when I overheard a remark in town," Ah it could have been worse only 5 died." The 5 they were referring to were the 5 white miners who had died. The remaining one hundred and seventy two black miners who died did not exist in the minds of some of these people. It was as if they did not exist as human beings. This was a life shattering moment for me and one that has lived with me ever since.

A year later I was part of the salvage team sent to recover the bodies of sixty eight miners who had lost their lives in a methane explosion at number 10 shaft Saint Helena Gold Mine. We spent six weeks at the bottom of what was left of the shaft working 10 hour shifts with no days off. I had never seen such destruction. The smell was horrendous as were the sights of 
mangled body parts but with the adrenaline pumping enabled me to get through. One experience during this period humbled me. I came across a safety helmet and part of a skull with the hair attached to it was in the helmet. The helmet still had the person's name on it. This humanised the event for me and I felt a sense of anguish, this had been some mother's son, some wife's beloved husband and some children's' father! All of a sudden I felt a rush of grief for these lost people welling up from within. That memory has also stayed with me.

By the end of six years on the mines I decided to get back to the city and study further.

I completed a Bachelor of Arts Curationis with Nursing Education and Nursing Administration as my major subjects. I worked in orthopaedics for a few years and noted that the curative model was paramount. There was no psychological, emotional or spiritual support for patients who suffered the loss of a limb or limbs. It was mainly due the resilience of the patients, the support of their families and a few dedicated members of the team that most survived this huge ordeal of loss.

I had various busy education, clinical and management roles up until nineteen ninety seven when I immigrated with my family to New Zealand. It was an exciting but emotionally tumultuous time. I began to know what it felt to lose an identity, to lose the touch and the closeness of friends and family. They were alive but so far away. I grieved my loss as I came from a close knit and loving family who cared and shared for each other. I knew no one when I arrived. I had one way air tickets so I had to adjust. There was no going back. I also had to adjust to a new concept called Bi-Culturalism. It seemed an odd concept to me a so many had strived and died to establish a multicultural South Africa. Being a South African in a new country was a major culture shock. I spent much of the first six months giving history lessons about South Africa and that not all White South Africans had supported the system of apartheid. I was even asked how many slaves I had owned? I began to feel an affinity for how ordinary German folk must have felt after the Second World War as many had not supported or knew what the Nazis had really been up to. We knew there were sinister things going on but the press was muzzled and those who protested vehemently were arrested without charge and some simply disappeared never to be heard of again. One would also get threatening phone 
calls from the security police if they suspected that you were in collusion with anti-apartheid activists. Because the black population lived separately we did not witness what was really happening and what struggles that they endured in their daily existence.

In New Zealand I worked as a staff nurse on the surgical ward and enjoyed the close contact with the patients. I was no longer just busy with the doing part of nursing I was listening more and noticing more. I was more attuned to their feelings, their fears, their journeys, their stoicism, their trust and mistrust, their pain- physical and non physical. They were no longer just patients with diseases that had needs they were fellow humans on the journey of life. Each was unique but shared this common humanity. I noted that much was done according to protocol. Patients received opioids according to what surgery they had received. Some nurses felt that the patients could become reliant on the analgesia and were reluctant to use adequate amounts. The acute pain service speciality was becoming stronger and this led to individualised pain scoring and management.

I also became acutely aware of the lack of communication with patients. Many were fearful of impending procedures and surgery not so much because of the procedures themselves but due to a lack of communication with these patients about what the impending procedures or surgery entailed what they were for, what benefits and possible side effects could be. During this time I enrolled to do a post graduate certificate in nursing. One of the papers I chose to enrol for was The IIIness Experience. I was exposed to the world of the patient in a new and revealing light. through existentialism and phenomenology. I had previously brushed with existential thought in the writings of Frankl $(1959,1996)$ and Kubler Ross $(1969,1996)$ but not with much emphasis. I read some of Max van Manen's (1998) writing on IIIness and was fascinated by his findings. A lot of what I had been taught and experienced was about surmising. This new study encounter revealed more about knowing from the patients' experience. The only way to understand the patients' world was through listening and exploring with them. This paper had a profound effect on my thinking as a nurse.

According to Glen Elder's Life Course Theory this could be realised as a turning point in my nursing trajectory. (Daaleman \& Elder, 2007). Understanding illness from the individual 
patient's gaze became an integral part of my nursing practice. I was no longer blinded by my own gaze or my professional gaze of their illness experience. I was again enthusiastic about my nursing practice. I could see each day as an opportunity and a challenge to engage with patients in a new way. My days were no longer just filled with mundane tasks to get through. These tasks were important but there was so much more. I could not live the experience of a patient as it was their unique lived experience but I could be more open to ways of knowing and engaging with them and their experiences.

In 1998 I became an after hours clinical resource nurse working across the whole hospital. This role covered emergency response calls, trauma backup, wound advice, intravenous access, advice on protocols, attending all arrest calls, debriefing, pain control issues and any other technical or clinical queries after hours.

In this role I witnessed many cardiac and respiratory arrest situations and situations which often resulted in death. I noticed that patients in the cancer, haematology and palliative areas seemed to have more peaceful deaths than those who died in other areas. I also noted that death was more acceptable in non surgical areas. In surgical areas death was often seen as failure and the enemy. I often witnessed families of patients and nurses in the non cancer areas in real emotional turmoil after witnessing the death of a loved one or patient. I organised and sat in on many discussions and debriefing sessions to know that the death experience of many patients, their families, loved ones and their nurses was not optimal.

During this time I came across an eighteen year old male patient whom I escorted him from the post operative recovery unit to the surgical ward. The staff in the unit were in shock. They were expecting a non complicated post operative patient not one with extensive tumour invasion with a terminal prognosis. I joined in the discussion of how sad this all was but all was temporarily forgotten in the business of life.

Six weeks later I was asked to put in an intravenous catheter into a patient and on entering the room immediately recognised the young man. He was in pain, distressed and had lost an incredible amount of weight. I looked in the patient notes to check what had been happening 
and there was no mention of a referral to oncology or palliative care. In fact in casual discussion with the family and girl friend it was apparent that they expected him to get better and that these were just post operative setbacks. I contacted the registrar on call and asked why the patient had not been referred to oncology. He agreed with me that six weeks was too long and the patient was seen the following week.

Over the next sixteen months the family could not accept that their loved one was dying. They tried alternative treatment, overseas experts to no avail. In the week before his death his mother was pleading with the nursing staff to leave his intravenous nutrition going so that he could go home for the weekend and at least experience sex with his girlfriend. I have pondered over and over whether the suffering of this young man and his family could have been avoided with some frank and open discussion by the initial surgeon and early referral with professional support at hand for the family? This dreadful scenario played out in my mind for many months. How could palliative care become more accessible for patients in non cancer areas? One could say this was another defining moment in my nursing trajectory. I gave a presentation at the New Zealand Surgical Nurses' Conference (2007) titled "The role .of palliative care in the surgical environment" which highlighted the problems I had witnessed and offered some solutions such as nursing in a palliative manner in general areas and that end of life care was also acute care for the patient and family involved.

A similar case involving a friend and colleague also had a huge impact on me. This colleague had been diagnosed with cancer for which she had surgical treatment. She was an outgoing and positive soul who saw this as a lifestyle challenge and was soon participating in demanding sports. She kept on getting recurrent backache which was attributed to her demanding exercise regimen. Eventually after many months she had a scan which revealed extensive metastatic disease. She had chemotherapy, radiotherapy and was eventually told that there was no more to be done medically. What affected this good friend the most was the statement that she should not pursue alternatives as this would only lead to a lot of expense and very expensive urine. She felt that her hope had been snuffed out by this statement which was said in a matter of fact fashion. She took this up as a personal challenge and tried many of the alternative therapies with little physical benefit. 
I recall one admission of many where she was brought into the accident and emergency area due to severe headaches. She was placed in a busy passage with a lot of thoroughfare under glaring lights. That's how I knew she was there. I had walked past and recognised her whilst walking in the passage. I was fuming. How could the staff do this? Here was a patient who had a very visible and high profile job at the hospital lying in a busy thoroughfare where everyone who worked at the hospital would notice. I arranged to have her put in a darkened resuscitation bay with dimmed lights until a bed space become available. Another defining moment. What had we as nurses become if we treated our own in such an uncaring manner? What was going on? There was a shortage of staff and beds but did this excuse us from being kind and giving a little thought to those under our care? My good friend and colleague died not many months later and I vowed to myself that I would do what I could to challenge what I had witnessed and was witnessing more and more now that I was more aware.

Over time as a resource nurse I became more aware of the palliative team and their approach. I was asked to give a presentation to the Palliative Care Study day which I called the Loneliness of Dying. In this I explored the work of Norbert Elias and Kubler Ross. I was asked many times why I did not do Palliative Care as I was such as strong advocate for patient accompaniment in their journey and also end of life care. This constant gentle persuasion led me to enrolling for the Post Graduate Certificate in Palliative Care and the beginning of my formal journey in Palliative Care.

\section{Summary}

Writing my own life story has offered me the opportunity to identify the turning points in my life. I have become more sensitised to how I think and interact and interpret what is happening to the people I engage with daily. The challenge is to continue to write as a way to reveal my thoughts and practice to myself. Johnstone, (as cited in Levine, 2006) wrote that one's own story is a never-ending one as it remains open "...to be revisioned and retold as new understandings, insights and meanings are brought to it by the experiencing interpretative interactive self' (p.31). 


\section{CHAPTER SIX: STORIES REVISITED}

\section{Introduction}

In this chapter I revisit the narratives in Chapter Four after having written my own narrative. The insights I gained about the nature of the turning point and listening with compassion were starting to surface. In documenting my reflections on these stories how I was processing the deep story is lifted to the surface in my awareness.

\section{High Anxiety}

Initially I dealt with Bob's anxiety and rambling statements more as a bystander or curious onlooker than through my professional experience. I realise that at first my feelings of empathy were directed more at the plight of Bob's family. When I did connect with Bob it was through physical touch that I was able to perceive and respond to him. It felt good to be able to care for him in a more meaningful way. Bob had found more spiritual peace. I realised that I had witnessed his frail humanity through embodied presence.

At this stage of my nursing journey I experienced patients mainly through story and reflection. My listening to them at first was quite casual. I realise now that I was making 'small talk' rather than really listening to Bob. By small talk I mean discussions about rugby, current news events and such like trivia. I was filling in space but not really engaging. It took my reaching out and making a physical connection through touching Bob for me to experience that something deeper than just the physical was happening.

What I had read about body and spirit connection was being revealed to me in that encounter through touch. I was able to experience his spirit through physical connection hence my insight that he did feel supported spiritually. When I wrote the initial text I did not identify that this had occurred. I knew that something had moved me but that I had connected to spirit though touch would take time and a lot of further reflection. 
Connection with Bob came through physical touch. I became a witness to his frail humanity through embodied presence. This enabled me to perceive and respond more to his spiritual questions and needs.

I felt good that Bob had found more spiritual peace.

\section{To Be or Not to Be...}

Reacting firstly to an emergency situation. Going through the motions. Connecting with Maggie physically at first through gagging at the stench. Reacted by imagining what the taste and experience must be like for Maggie. A different type of connection was occurring. I was already present for her physical distress but projecting my thoughts on how it must be for her.

At first the connection concentrated on the physical because I was trying to imagine how I would be physically experiencing what I was witnessing her going through. I watched attentively for physical cues. I noted her eyelids flutter then open and witness the terror in her eyes and expression as she realises what is happening to her. I advocated on her behalf and there was a positive response. Resuscitation is stopped and the endotracheal tube removed. Maggie nods and squeezes my hand in appreciation. It is a knowing response from Maggie. A response that reveals that we share our frail humanity.

I realised that it was through compassionate listening and attentiveness that had enabled me to connect with Maggie and advocate on her behalf. I felt as if I had done something meaningful and realised that it is through these types of encounters with patients that I am sustained and enriched. It is the knowledge that my practice has meaning for me as well as for my patients.

\section{The Arrest}

I witnessed the anxiety, compassion and kindness in June. I also witnessed the compassionate response in myself for June in the situation she finds herself in. There is an element of knowing as I have lived through this angst myself before. The feelings of guilt and helplessness experienced through an uncontrolled situation. 
Experience has taught me that to be a true role model I have to put myself in June's head space for a moment. In being present for and with June she is able to calm herself and continue with the painful task at hand. In reflection I have come to the conclusion that compassion is non judgemental.

\section{Trust}

Compassion is not just an automatic response in me. My bias towards Aroha and her non compliance was a judgemental response. I had not listened to her story or experience. My mind had been clouded by its own biased conclusions.

However by actively listening to Aroha's story and the reasons for her non compliance I began to be moved by her relating her situation. Listening actively evoked a physical response in me through tears. An embodied connection had occurred.

In our next meeting I was more open to her humanity. We could sit in each other's presence in silence and connect. Compassion for another had led to this place of safety for both of us. The compassionate being in the moment with each other and connecting is nourishment for the soul. Nourishment brings about contentment and healing for both myself and Aroha. But I have to remind myself that the feelings I experience are my own. However, Aroha's body language and what she says enables me to realize that something positive has happened for her during this encounter.

\section{Summary}

In identifying insights that occur in each narrative in this chapter I have been able in this chapter to literally move forward in my own level of engagement.

On deciding that I was going to use autoethnography to delve into my story and the stories of some of the interactions I have had with some chosen patients in practice I developed a pattern of reflection in where I would reflect and then reflect again until the essence of what I was doing or trying to do would be revealed through the writing. I was looking for insight into 
the connectedness I had in each situation. Maybe a pattern or theme or something deeper about my practice would be revealed through this process of writing and reflecting on practice narratives.

When I initially started writing the stories I found that the writing seemed stiff and uncomfortable. I had to grapple with myself. What was I trying to achieve? The writing seemed deeper than simple recall. It was a way of shaking me out of my usual complacency. I found that as I wrote more a questioning self emerged, a critical self. I discovered that I started reflecting on deeper aspects of life and nursing. As I reflected on a patient encounter I began to note what seemed meaningful for me and for the patients' I shared with and cared for.

Writing about how I witnessed a patient's journey was easier than reflecting on myself where ego had a habit of getting in the way. However, the more I wrote about my practice the more I found out about myself and how I engaged with others and the world around me. In the beginning I pondered whether my reflections were only relevant to myself. Was what I was writing about only important for my own practice? Sharing some of my stories with other nurses in the initial stages of my post graduate journey with was difficult. I felt naked and exposed as I started to reveal myself and my practice through sharing narrative.

I recall when I shared High Anxiety for the first time in a class with fellow students. I noted the silence around me especially when I revealed how I had experienced mutual healing through touch. I was more anxious about my presentation than perceiving what was really going on. The course lead lecturer when giving feedback made me realise for the first time what an impact sharing my story had made on other nurses. This encouragement that sharing narrative could make a difference was a defining moment for me and in fact was the seed that led to the growth and development of this thesis 


\section{CHAPTER SEVEN: MOVING FORWARD}

\section{Introduction}

In this chapter I bring the insights gained in my practice world to bear back on my own life story. I identify the most challenging aspects that have occurred in my own life and find a new level of integrity between my personal and professional life.

Most of my nursing experience has focused on the trauma, surgical and general nursing resource areas. Many of my nursing years were spent working shifts with long periods of night duty. I had a few personal health scares and lost a 39 year old brother to cardiac disease in 2008. This was during the writing of this thesis and I decided to have a change in nursing focus. I had completed a Post Graduate Certificate in palliative care nursing before my Masters and wanted to continue to focus on my studies and experience of compassion. Palliative care would also give me more opportunities to engage with patients who were in the terminal phase of their bodily existence as well as with their families.

Being in a palliative environment would also allow me to explore more deeply what goes on during those special nursing-patient encounters. I knew from past experience that compassion in nursing is by no means exclusive to the palliative arena but I considered that I would have more time to focus my thinking around the engaging encounters that I have experienced through being open and trying to practise my nursing with compassion. The choice of a practice philosophy based on my understanding of compassion has bridged that gap between literally not knowing and feeling fearful of saying the wrong thing. I no longer avoid what I had previously felt were difficult encounters as I know now that in conversing with a patient and their family with kindness and compassion I can usually create a positive outcome or an outcome in which some meaning has developed or occurred.

The six narratives described in the text reveal challenging situations documented in the way a nurse experienced them and each reveals an outcome that could be described as being positive in terms of palliative care principles enshrined in the World Health Organization (2002). These principles are: 
- Provide relief from pain and other distressing symptoms

- Affirms life and regards dying as a normal process

- Intends neither to hasten nor postpone death

- Integrates the psychological and spiritual needs of patient care

- Offer a support system to help patients live as actively as possible until death

- Offers a support system to help the family cope during the patients illness and in their own bereavement

- Use a team approach to address the needs of the patients and their families, including bereavement counselling, if indicated

- Will enhance quality of life and may also positively influence the course of illness

- Is applicable early in the course of illness, in conjunction with other therapies that are intended to prolong life, such as chemotherapy or radiation therapy, and include those investigations needed to better understand and manage distressing clinical complications.

The reality is that often only one of the goals is attempted or attended to in the acute care setting where death may be occurring very rapidly. While the narratives demonstrate a range of situations, what I discovered was that my insight into what was occurring for the person was enhanced by my growing ability to show compassion.

Compassion has added what Frankl (2006) termed "meaning" to my nursing practice. I am no longer just concerned with my being, my career. Through compassionate awareness I have become more aware of the human and health care needs of others. This awareness has enabled me to frame my observations of the patient, through maintaining an open and questioning mind. These statements are framed as questions but they reveal how I am thinking. How does this illness affect the patient and his/her significant others? How does the patient and his or her loved ones experience and cope with suffering? Is the nursing they experience bringing some meaning to them or is it just another mundane experience? Is the patient's total wellbeing and health enhanced by my and others' nursing practice? These are the sorts of questions that I am able to engage with in a more meaningful and scholarly way 
within palliative care speciality practice. I consider that this way of being and knowing will continue to unfold and will enable me to experience new ways of knowing.

The work setting in large acute care hospitals is highly competitive. This is challenging when I mobilise my compassionate being to attend dying patients. Nouwen and McNeill (1983) point out that it is difficult to be compassionate in a world that embraces competition. They say that competition, not compassion is a human's main motivator in life.

This all-pervasive competition which reaches into the smallest corners of our relationships prevents us from entering into full solidarity with each other and stands in the way of our being compassionate. We prefer to keep compassion on the periphery of our competitive lives. (p.19)

Perhaps this explains why I have found it so surprising when I have received exceptionally positive feedback from colleagues.

I believe through our special and unique relationship with patients when it is born out of compassion can challenge this world view. We can become the leaders of compassionate care and role models in a broken world that demonstrates unfeeling, uncaring, individualistic, cruel, competitive characteristics. Roach (1987) supports this emphasis on compassion in her writing:

In an age where the scientific and the technological are weighted heavily (and often favourably) in human progress, the need to emphasize the humanizing ingredient of compassion and the need for the cold and impersonal world of science and technology to be infused by things of the spirit is urgent. (p.61)

In a more recent article Schantz (2007) cites Tsuchudin and Schmitz's view that: at this crucial moment when professional nurses are summed up to answer the challenges that will impact the viability of our profession as well as the viability of humanity within the global context. It is compassion, in my view that lends itself to be recognized, internalized, and applied in everyday nursing practice. (p.53) 
Schantz (2007) states: that "compassion has its own intrinsic and spiritual empowering values" (p.53). She quotes Dietze and Orb (2000) who remind nurses:

Compassionate care...is not simplistically about taking away another person's pain or suffering, but is about entering into that person's experience so as to share the burden in solidarity with them and hence enabling them to retain their independence and dignity. (p.53)

\section{Summary}

I have realised that nurses are challenged not only to be aware of and assist in alleviating patients' suffering but also to show a new way of being in the world by being compassionate. Nurses can strive to become the leaders and role models of compassion. In the next chapter I will document several more narratives to clarify the reflective process that is evolving in my practice. 


\section{CHAPTER EIGHT: STORIES MOVE ME}

\section{Introduction}

In this chapter I am using the insights that I have gained through using the autoethnographic method, writing practice narratives and my own life story, to reveal the nature of turning points occurring in the process of using compassionate listening. In this chapter I aim to increase my insights into compassionate listening. This chapter presents two further stories.

\section{Jean's Tears}

Jean arrived for her first out patient clinic appointment for Palliative Care with her husband Steve. When I entered the room I could see and sense their fear. It was written all over their faces and their mannerisms. I introduced myself as a Palliative Care Nurse Specialist and with the mention of the word Palliative Jean burst into tears. Tissues were immediately at hand. I encouraged Jean to let it all out for a while but I was feeling a bit uncomfortable to say the least as I had never experienced a response such as this on initial introductions.

Jean was a well presented and charming middle-aged woman who had multiple metastases. Further scans revealed that the cancer had spread and that the chemotherapy had failed. She was referred to palliative care for further care.

I had also recently joined the ranks of the middle-aged and so felt and immediate sense of affinity and connection with Jean. These were meant to be the prime years of life. I tried to imagine how I would have felt if I was in Jean's shoes. Would I be angry and scared and confused? Yeah, for sure I would. I knew that I could never experience what another person was experiencing but I sure could imagine what it may be like. I could not take her disease process or progression away but I could share with her and Steve and I could be there for them in the moment. I could offer them some time and the opportunity to ask questions or to just be in a space of safety and trust. This was about compassion for fellow human beings. Initially I had wanted to remove myself from the situation to offer a box of tissues and to come back a while later. Compassion for their obvious needs had kept me in the room. Silent at times and engaging at others. Being there in the moment with them was a privilege. 
The pain and suffering I had witnessed when Jean and Steve arrived stayed with me for a good few hours after the consultation. I reflected on discomfort of the experience I had just lived and it dawned on me that the discomfort and closeness in age had triggered a compassionate response in me and enabled me to engage with and care for Jean and Steve in what had initially been encountered as a nightmare visit for them. Without the connection that occurred through compassion I doubt whether I would have been able to care in a way that was both meaningful for the patient and myself.

I probed a bit and asked Jean why she was so scared of palliative care. She said that she felt palliative meant the end of her life was imminent. She had even failed to come to an earlier scheduled appointment as she had felt angry and abandoned. This was her body, she was not ready to die and she had the will to carry on living. Increasing pain had forced her hand and that was why she had changed her mind and arrived for the appointment.

I explained to Jean that although palliative care conjured up many negative ideas and emotions from patients and their relatives and friends we were not all about doom and gloom. Firstly we liked to introduce ourselves earlier rather than later in the piece so that patients and their loved ones knew that the service existed and that we could offer some solutions and treatment of their symptoms such as pain, nausea, anxiety, constipation, drainage of effusions and so on.

We functioned as a multidisciplinary team with a lot of professionals having specialist knowledge whose goals for her care would be aimed at making Jean's journey as comfortable as possible. Collectively, we would all aim to allay her fears. She could utilise us as she wanted to. From a distance through the telephone or electronically through email if she so desired. We would not hold it against her if she decided that she would rather not utilise our services. She was still in control and yes she may think for a moment that she was handing herself over to us in a fatalist way. We were available in whichever way she felt she needed us. Jean's tears did not dry up but there were some relieved giggles in between the tears. As Jean started to relax I felt myself relaxing as well. I felt more at ease in the conversation. 
Steve had been silent throughout the discourse between Jean and myself. In fact he had appeared anxious and defeated from the beginning. He had a mixture of foreboding and despair written all over his face. He tried to smile at Jean every now and then in order to encourage her but was struggling to remain strong and stoic himself. Every now and then the tears would well up in his own eyes and he would look away trying to hide his torment from Jean.

We spoke about Jean's pain. She had stopped taking paracetamol as she had heard it was bad for her liver. She had refrained from drinking wine or any alcohol because it was bad for her liver. I reassured her that she could take up to eight five 500 milligram doses of paracetamol every twenty four hours and that this type of dose was not toxic to the liver. I encouraged Jean to enjoy her glass of wine when she felt like it as her liver was not in failure and that the liver secondaries did not stop the liver from working and that she only needed a part of her liver to function adequately for digestive function. Her small intake of wine would not destroy her liver function. I encouraged Jean and Steve to enjoy the things they enjoyed doing and not to abandon living. Jean and Steve were beginning to look at lot less intimidated by this stage of the conversation and I was totally at ease and in my stride by this stage. I explained how the service worked in conjunction with hospice and their local general practitioner. I gave them the department's contact details and reassured them that they were as alone as they wanted to be in this journey but they could invite us on board at any stage.

I introduced the Palliative Care consultant to Jean and Steve and the consultation continued with discussion around symptom management.

\section{A Chain of Love}

I was asked to check on a patient Dawn, who had been commenced on The Liverpool Care Pathway of the Dying (LCP). I went to the ward concerned and checked through the patient's file. The first thing I noticed was how thin the file was. Dawn, a young woman had very seldom been ill, had collapsed a few days previously. 
Scans had been completed and revealed massive and multiple tumour activity. What a catastrophe! The medical team explained the scenario to Dawn and her husband Jason. They said that all an operation would reveal was what specific type of cancer it was and whether it was a primary or secondary cancer. Dawn, Jason and her mother Heather collectively decided against surgery and hence the decision to commence Dawn on the LCP. Basically the LCP provides for comfort care and symptom management using anticipatory prescribing. It is an evidenced based pathway of care designed by Professor John Ellershaw in 1997 to bring the hospice model of care into the generalist arena.

On entering Dawn's room I saw her husband Jason standing next to her bed holding her hand and her mother Heather sitting in a Lazy Boy chair on the other side of the bed. I introduced myself to Dawn, Jason and Heather and explained my role as a palliative care specialist nurse. I gathered from all present that little had been discussed re what the LCP was and how Dawn's anticipated symptoms would be managed. Jason appeared shell shocked and in a mind fog, Dawn was seemingly matter of fact about the whole thing. I could sense the emotional pain of a mother by looking at and listening to Heather. I asked if they had any questions or if there was anything I could do. I said that I wished I could wave a magic wand and take this nightmare away from them but was not able to. Heather said that what I could do for her was make her a cup of tea which I gladly did. I left the room feeling really sad for all concerned. I continued my other work and the business of the day helped distance me from what I had just encountered.

Later that day I checked back on Dawn and her two children aged six and four were present. They had returned from the local children's hospice support meeting and had been told by Jason and the counsellors what was happening to Dawn. The children looked bewildered but were filling in colouring in books when I entered the room. Dawn was not in any discomfort and said she wanted to be as awake as she could for the rest of what little time she had left. I said that we would respect her wishes but that she was not to try and be too brave and suffer more than necessary. I explained that we could adjust opiate dosages so that she would not be too sleepy. Dawn seemed happy with this and I then left for the day. 
I went home and did not think much more about the events of the day. I went to sleep but awoke at 0330 feeling unsettled with Dawn and her family on my mind. I tried to fall back asleep but kept on feeling disturbed but also thinking how tragic the whole scenario was. A thought came to mind. There is nothing you can do further but offer a circle of love. A what? The thought came through stronger. Offer a circle of love. I then felt more at ease and drifted back to sleep.

I visited Dawn and her family later the next morning and just chatted to all present. Dawn's sister and brother in law and their two children were present. Dawn's two little ones were being looked after by Jason's sister as they had become very restless in the interim. The two children were in tears as they had just been informed about their aunt's impending death. They settled after a short while and we continued chatting in general. One of the things Dawn wanted was a hair cut. Her mom felt that it was trivial but I could sense that it was hugely important for Dawn. I phoned the hospice volunteer coordinator and she said they would try to organise a haircut as soon as possible.

The thoughts of my early morning awakening kept coming back to me: a chain of love. Those present might think that I was crazy or encroaching into their domain. The more I resisted the more I felt prompted in my mind to do this. I said to all present that they may think this strange and that I had never done this before but would they like to join hands with me and Dawn and if we just concentrated on the love they all had for Dawn and to give it to her through our connectedness. I explained that love was energy and it could transfer through our hands to Dawn. I reiterated that if anyone felt uncomfortable or if those present had any objection then that was fine and we would not proceed.

All present seemed pleased to be able to do something positive and soon we were in a circle around Dawn's bed connected to her and each other with hands held. I then said "just concentrate on the love you have for Dawn and focus your minds on this love and offer it to her." I then asked all to be silent in the moment for a short while still holding hands in an embrace for Dawn. 
What transpired next was amazing. Dawn had been sitting cross legged and anxious on her bed. We were in a circle around the bed. A feeing of amazing peace and tranquillity filled the room. There was a feeling of closeness and warmth as well. When we opened our eyes and stopped holding hands, Dawn gently lay back and fell into a gentle sleep. I nodded to all present in the room and withdrew quietly.

The story about Dawn troubled me somewhat. Had I over stepped some boundary? This was very different to all other encounters I had previously had with patients. This was new territory. Somehow the experience felt surreal. It felt embodied and spiritual at the same time. Connections were occurring on a deeper level.

Again, I believe that through compassion I was able to reach out to Dawn and her family. At first I was considering my actions in a professional sense regarding comfort care at the end of life but then I was aware that I was exploring deeply with those involved. The chain of love experience had brought a sense of healing to all present. I know this because I came across some of those present in the days after the event took place and they told me of the wonderful feeling of peace they had experienced and thanked me. I know that a circle of love would not be appropriate for some patients and families but I followed my heart and intuition and healing had occurred. I also came across some writing by Watson (2005) that supported my practice in this instance:

Perhaps it is love that underpins and connects us through our metaphors of facing and holding another in our hands, reminding us how to sustain our humanity at a deeper level at this point in human history. (p.199)

Watson goes further to state: "So rather than how can we dare to bring love and caring together into our lives and work? We can ask: How can we bear not to?" (p.200).

The story of Dawn led me to reflect further on my practice. A process in my practice as a senior nurse seems to be revealing itself through the stories. On entering a patient's room or space I observe what is happening to and for the patient and their loved ones. Are their physical needs being met? Do they look happy, content, sad, lonely, shocked, bewildered, apathetic or withdrawn? 
Before engaging further I am mindful that I have to focus and clear my mind of lingering or distracting thoughts. This focusing enables me to become present for the patient. Is the patient able to communicate? Do they want to communicate? Do they feel at ease in sharing their thoughts and feelings with me? Do they like touch or do they flinch or pull away when I touch through shaking hands with them. Are they positive about their care and have an air of acceptance about life's happenings or are they negative and anxious? Are they at ease with those visiting or are there some cues that not all is well with the relationships in the room?

These are the sort of questions I am conscious of thinking about as I take in the whole of what I perceive in the unfolding scenario taking place. I then consciously envisage what this illness experience must be like for the patient. I then engage in conversation about how they feel, what they are experiencing, something about home and family, a question about a photograph and such like. I then try to find some common ground with the patient be it interests or hobbies or sports. Throughout the conversation I register the responses and listen compassionately in order to gain some insight into the patient's emotional, psychological, cultural and spiritual well being. Does what the patient shares with me have meaning for me and meaning for the patient? Does it have meaning in regard to the planning of care for this patient?

Sometimes the patient unfolds and reveals some of their inner core by sharing deeply. During this time I am mindful of allowing this sharing to take place, to nurture it and to acknowledge it. This is often when the spiritual is reached and when our frail humanity recognises love. This love is given, shared and responded to so that inner healing takes place for the patient and the nurse. There is a mutual recognition that something special has occurred. It is a peaceful, harmonious experience and there is often a stillness that captures the moment or moments in time. So this is it in a nutshell: the heart of compassionate listening is the realisation that people feel loved and that healing takes place. In further reading I came across two gems by Watson (2005) that supported what I had realised:

- Caring and compassionate acts of love beget healing for self and others:

- Listening with compassion and an open heart, without interrupting: listening to another's story is a healing gift of self. (p.201) 
If I think of the four stories I wrote initially I can now see similar threads in all of them. These threads are compassion and listening: taking time to allow a focus to occur and allowing love. The actions that support such practices centre on an ability to engage, focus, listen compassionately, reflect on what is going on, respond and share, recognise frail humanity and oneness with the world, give love and be open to receive it. Realise when healing has taken place. In reading the literature I came to realise that the importance of compassion and love as part of the Art of Nursing became lost due to the concentration on measurable and quantifiable nursing tasks. As Wilkinson (1995) described: "Because the affective domain of caring is not easily measurable it is not normally considered in quality assurance tools" (p.985). Wilkinson pointed out that nurses have an obligation to advocate for change and "to help create a culture of love" (p.986).

Fromm (as cited in Wilkinson, 1995) stated: "To have faith in the possibility of love as a social and not only exceptional individual phenomenon, is a rational faith based on the insight into the very nature of man" (p.986).

Through writing about the encounter I found that I could practise with awareness that being compassionate involved a process of deep listening. I could practise systematically and then through reflecting on each encounter and rewriting it from a deeper perspective and documenting the deeper reflection, I discovered a way of being compassionate in the heart of myself and artistry in my practice.

I have learned that the simple act of recognising Dawn's need for a haircut led to a cycle of compassion. She had mentioned that she wanted a special birthday for her youngest child. I mentioned this to the Hospice volunteer coordinator who managed through a volunteer to get Dawn her haircut. Once home not only was her wish for a special birthday with ponies organised but volunteers came forward to give Dawn a facial and makeover, a professional photographer donated time and made an album of photographic recollections of the special day. My thoughts are that once compassion is initiated further compassionate actions can be realised. According to Kubler-Ross (1997): 
There is within each of us a potential for goodness beyond our imagining, for giving which seeks no reward; for listening without judgement; for loving unconditionally. (p.238)

I know how compassionate listening has developed and brought meaning to my practice as a nurse but how can I show other nurses how compassionate listening can develop their nursing practice?

I could share compassionate listening with a new graduate nurse as a structured way of thinking and being. I could encourage them to observe and then focus on the patient. I would then ask the nurse to write down her observations and thoughts and reflect on them. Some time could be set aside so that we could mull over the written observations and thoughts together. After this I would encourage the graduate nurse to rewrite and explore their thoughts more fully to see if any other conclusions could be arrived at. This I believe would build capacity in junior nurses and to develop the disciplined practices that are revealed in an embodied knowledge of practice.

It is I believe important to explore compassionate listening with new graduate nurses so that they can realise their own capacity towards being compassionate, actively listening and hence allowing healing through love. This will strengthen their practice and give them tools to focus and cope with the ever growing demands of the managed health care environment.

I am suggesting that an embodied knowledge of being compassionate is where I have found a way to be whole in a busy and business oriented health care environment and contribute to excellence in patient outcomes. I would also suggest that practice is always context specific and nursing contexts and particularly palliative care contexts always depends as much on colleagues as oneself. This will become evident when I describe the next step that I took which was to share my practice in written form with colleagues so as to find a new level in our conversations especially around the nature of compassion. 
In sharing my stories with an audience I could aim to bring about change in practice toward compassionate listening. Kidd and Finlayson (2009) pointed out that:

members of the audience as possible agents of personal and cultural change and aim to motivate the audience to examine their own lives in response in order to bring about a change. (p.982) 


\section{CHAPTER NINE: SO WHERE TO NOW?}

\section{Introduction}

In this chapter I ask a provocative question and reveal how I engage with colleagues. Do my stories and reflections strike a chord with other nurses?

The questions that I have pondered over the years about the seeming lack of care with regard to non physical healing of patients have led me to believe that I as an individual can make a difference with regard to a patient's healing.

For many years I thought it was by communicating and talking to the patients that I would feel some completeness in my nursing practice. However I found that often I was just making idle conversation and was not really connecting fully. There was something missing.

I then thought it was all about active listening. There was a better connection with my patients but not a strong one. During my studies towards writing this thesis I started looking at compassion and caring. The words just came together during lectures one day: compassionate listening. I experienced such a buzz of excitement. I had been listening over the years to my patients and had always believed that being kind was important.

The simplicity of the words was reassuring. However, the more I explored the more I realized that although the words sound simple they can be a challenge in practice. It is not easy to be compassionate to someone who irritates or annoys you. It is stepping behind the irritation or annoyance that the gems of practice are often found.

In a nutshell compassionate listening for me entails truly being there in the moment for the patient or their loved ones. To brush aside hostility, anger, and fear is to reach deeper and listen for the care needs of the human behind the façade.

At first this type of relationship with my patients did not always occur. It took conscious effort to relate in a compassionate mode. Now the practice is embodied in such a manner that 
compassionate listening has just become part of my practice and who I am as a nurse and as a human being.

\section{Do My Stories And Reflections Strike A Chord In Other Nurses Or Is This Writing Just About My Individual Practice?}

I often wondered as time progressed what my experienced colleagues would think about how I articulated my practice. Even though I engage with them closely when we are making decisions about care for and with patients, it requires an allocation of time to converse about the dynamics of practice. Large hospitals are constantly evolving and a lot of energy is absorbed in the constant change processes. These processes ostensibly focus on patient outcomes and only recently have begun to map the patient journey. This narrative is bounded by the time in the service and the progression of the pathology the person suffered from. To take time regularly to engage with colleagues to share one's thoughts about developing oneself and one's practice requires dedication to the task in hand. I asked a very poignant question that is often posed to beginning nurses who are trying to demonstrate that they have created a way to respond to the question: how does one make space in practice for magic to happen?

I engage regularly with colleagues in conversation about the structure of our work and how we should conduct our practice. We discuss performance development and as we act as mentors we consider processes for engaging as mentors with staff who are learning to engage in more advanced roles. We tend to use conversation as the classic mentoring process and writing of exemplars as the second most obvious style of development. I had no problem in asking colleagues to read texts that I had written to advance my own practice. I began by asking them to read three of my stories with accompanying reflections. I then asked them to read the text Transitions in a Nurse's Life journey and finally the reflections on the three stories written after I had written my own life journey.

Kleinman (2009) highlights a statement made by Ellis (2009) “...we will not know if others' intimate experiences are similar or different until we offer our own stories and pay attention to how others respond, just as we do in everyday life" (p.143). 
The stories I chose for my colleagues to read and reflect on were High Anxiety, The Arrest, and Trust. I assured them that I just wanted them to read the texts so that we could chat about them and that they were in no way obligated to write anything. I impressed on them to be as frank as possible in their reflections on my writing. My colleagues had known for some time that I was engaged in closely exploring listening and the nature of compassion. I explained that our conversations and their reflections would inform my practice.

I was astounded at the responses I received from these colleagues. They were forthright and disarming in their frankness. They were generous and uplifting. I felt that I had been seen and heard. I knew my colleagues to be generous in their verbal comments but their written responses amazed me. These texts show the tone of our engagement.

\section{Colleague One}

I gained some extraordinary new insights from your writing...the most profound theme that came through for me was your own conclusion around the importance of being able to get your 'self' out of the way in the encounter to allow the true need to be revealed...the idea of elevating the role of listening from another 'task' to a potentially transformative part of the nurse/patient encounter is particularly powerful.

This respondent also said that she felt that instead of following a process, the stories need to be shared so that "the embedded meanings and knowing" could be reflected upon.

\section{Reflection}

Reading this reflection was revealing in how my peer gained insight from my writing that the self must be put in the background rather than the foreground in the patient encounter. I was awed by the respondent finding that sharing and reflecting on the stories can reveal "embedded meanings and knowing." This confirms what I wrote earlier in the thesis about the importance of sharing stories because I have noted over the years that nurses are seemingly more attentive and reflective when stories are being told. One only has to attend a conference where patient or nurse stories are shared to note how much more reflection and sharing occurs during question time. There is something about the patient and nurse that becomes more real 
to the audience through story. Nurses are interested in the nature and revelations gained about the human condition especially the ill or suffering human condition where nurses feel they can relate and intervene to share and alleviate the burden they witness in everyday nursing practice.

\section{Colleague Two}

Your writing...has certainly made me reflect on compassion, listening, meaning in what I do as a nurse. For many it is not something that comes naturally... Through experience you learn that there is more to nursing than the technical/task side. The greatest rewards are in what you don't see -the caring compassion, connection, listening side. Through telling your story and sharing your experiences I feel it will help nurses to get to that place a lot quicker, open their eyes and help skill them to understand the true art/essence of nursing.

\section{Reflection}

When reflecting on what my colleague revealed regarding compassion not coming naturally to many I realised how cultural background differs. Often when I think nurse or nursing I think of a collective professional whole. I realised that I was somewhat arrogant in my thinking. I had a loving childhood and supportive parents. Not all nurses have had the positive experience that I had during my upbringing. In other words I must be aware that when I share or talk to nurses about my stories there will be some who do not relate to the world and their patients in the same way that I do. I must therefore challenge myself to listen to their stories and value their insight so as not to be biased by my own.

\section{Colleague Three}

As nurses we share the honour of being trusted with often the most vulnerable moments in our patients' and their families' lives. Listening to the stories of those vulnerable people we see on a daily basis allows us to grow as humans, sharing the trauma, joy and sadness that inevitably confronts those with a life shortening condition...I often fly from one patient consultation to another with much noise in my head that often needs a quite moment to quell. Reading your reflection reminded me how important this was to enable compassionate listening and in making a vital connection with the person in the moment. I 
realised how important it was to pause before entering into another relationship that required this special connection...Achieving compassionate listening or making that very special connection which always involves two people-the patient and the professional, is what nurtures our care and ability to offer respite. Call it love connections if you will, love for humanity and the frailty which we all face, and the recognition of this in each other.

\section{Reflection}

I found this colleague revealed something to me that I was not conscious of highlighting in my writing and that is to pause and reflect. To soak it all in and see the other before continuing. Also to pause and reflect between patients. Great stuff as I have often bowled straight into the next patient situation and have felt distracted and hurried. This could easily be picked up by patients and interfere with the nurse-patient relationship from developing. I was reminded of the old adage that initial impressions count and could be lasting ones. So in order for compassionate listening to take place and be effective I as the nurse must ensure that my head space is at peace before I initiate the encounter.

\section{Colleague Four}

Peter's [work] contributes to the understanding of how developing the ability to listen can develop the relationship that leads to the well-being of the nurse and patient in their mutual life course. This is important for the nurse to enable him/her to have meaning for what they actually do and the suffering they witness every day...As we as nurses grow in our profession as well as maturity in years we change, and the view of how we see and experience things rarely remains the same. Some of us become cynical and some of us use the experience to enrich our practice and enrich the lives of others-as in Peter's [work] is evident...it is important to engage in patient's stories and be with that patient in that moment and time. I can see this becoming evident in Bob's story and that the ability of Peter to be present and not presumptive about alternative therapy...he actually helped this man to face his actual fears which were spiritual...The heart of compassionate listening is indeed the realisation that people feel loved and that healing takes place. 


\section{Reflection}

When reflecting on an experienced colleague's reflection the thread that struck me was that meaning is so important in protecting nurses from the suffering they witness every day. If nurses find meaning through compassion and in finding a meaningful outcome for them and their patients this in turn assists in the prevention of burnout which has become more and more prevalent in nursing. One hears a lot about "compassion fatigue". Is this fatigue really caused by compassion overload or by being overburdened with a myriad of tasks that eventually have no meaning for the nurse? I would suggest that because of the emphasis on outcomes and fulfilling contracts in modern healthcare facilities, what is done to the body takes precedence over how you feel. Because of this the dignity of the patient and the nurse is compromised. The patient feels like a sausage and the nurse feels like being part of the production line over which he/she has no power to intervene. This feeling of powerlessness and abandoning the patient is I believe what leads to the fatigue and burnout by been thwarted from being able to be compassionate.

\section{Colleague Five}

Reading your [stories] on compassionate listening was a catalyst in re evaluating my relationship with my patients and their families. Some days are hectic requiring one consultation after another. These interactions with people are often complex requiring assessment of the physical social and psychological impact of their degenerative condition. After reading your [work] I had a particularly busy day with two complex situations. On entering the second relationship my mind was still on the first complex array of problems presented to me by that patient. I suddenly found myself going through the motion of greeting, assessment and discussion with little focus on the words that were being used.

Your words on compassionate listening and love, being in the present flooded into my head and helped me focus on this very special person requiring my full attention. We went on to talk about end of life decision making and tears were shared. A connection had been made once I fully presented myself in the 
moment. My patient and his wife were able to discuss their concerns and share their distress and I was honoured to be part of their journey.

\section{Reflection}

I was in awe of these reflections on my stories and thesis. I was amazed because I realised that I was expecting at least some negativity or criticism from my peers. Their responses were overwhelmingly positive. They made me realise that my texts were not just about my own practice and self indulgence but that these colleagues could sense similarities in their own practice. The experience of love and meaning had rung true for them too and they could concur that compassionate listening is an important part of practice. Their responses also confirmed what I had believed for many years in that sharing story or narrative could evolve and add meaning to practice.

\section{Summary}

In this chapter I have had reflected back key insights from colleagues about the nature of compassionate listening. While I have been almost overwhelmed by their positive affirmations of what I was doing, what is revealed is that we are learning to consider what really matters and produces positive outcomes for the most vulnerable patient-the person who is dying. The best affirmation from a colleague is not praise but when someone tries out what I do in practice and finds that it works for her in her nursing practice and this gives me impetus to continue in my quest to develop my practice and accompany new nurses to develop theirs by promoting the importance of compassionate listening in practice. 


\section{CHAPTER 10: CONCLUSION}

Using rhetorical and philosophical questions, I have shaped the foundation of my practice. I have described a life lived initially in South Africa and shown both myself and my colleagues how twists and turns in this early life, which included my nursing training, have indeed profoundly shaped my ways of practising nursing. I have made a transition from using questions as a way of searching to describe the world and to explore who I am, to using questions to witness more of what is possible in my life and practice. I discovered that while I was used to engaging on a day-to-day basis as a shift-based nurse, when I became a nursing leader, openly guiding and mentoring colleagues and organising service changes, it was important to be able to fully articulate my insight into how my own life story had shaped my practice. This insight became my own turning point.

I began to explore the original question in my thesis which was aimed at considering the nature of listening and especially compassionate listening. Initially I had concentrated on exploring and promoting compassionate listening because I needed to have a good case on which to base my argument for time to talk with patients and time for training and support for colleagues who practised in this manner. I knew that in a cost-driven health service leaders are explicit about their use of models of care such as the LCP (2003), successfully arguing increased patient engagement and better outcomes (Chiarella, 2007).

Simultaneously I had been using a disciplined process of documenting exemplars and reflecting on these narratives systematically over many years. Like many colleagues I found this process nurturing and sustaining but something had changed. I found a way to engage with patients and their families which is immensely satisfying and respected by colleagues. Being able to document exactly how I achieved this was important. I created a stepping stone process, moving between my own life story and writing practice narratives. Previously these two texts had been separated and when I placed them together in this thesis I began to reveal the hallmarks of my practice.

I began this thesis with the two questions which became exploratory goals and I considered that each question expanded my awareness of self and my practice. I have summarised my 
concluding position in relation to each question. The first question wash how does deep inner story reveal insight into being human and particularly into how nurses care for others?

I answered this question by engaging in sharing my own life story as a journey to reveal that a life course journey has transitions that create bridges between events. In the process of transition I recognised the nature of transition as having many twists and turns that need to be negotiated. I know that at times I am the bridge and at other times I am interpreting the journey of the twists and turns with and for a patient as their body or experience is trammelled by what they are going through. By spending time with a person and listening in the particular way that I have described, I found that I was able to tap the deeper aspects of a person's life and circumstance. It is often considered to be the case in research that interviews to establish the life history of a person may take approximately half an hour. An hour may be allotted if the person is very ill and frail but in my work setting there is often almost nothing able to be shared; consequently I have to scan the whole setting in order to see what the situation is presenting to me and find a way to engage meaningfully with the patient and their family or loved ones. I have found that the fraction of a second taken to stop and see the person and to take in who they are as a person enables me to connect with them in such a way that they feel recognised as a human being and not just a person in crisis. The insight for me is that I realised that I was able to make this connection before I worked on them physically and technically, even in the context of resuscitation. This realisation made a world of difference.

Prior to conducting this research I would have said I did not really know what it was that had occurred in practice. Now I can say with some assuredness that I can see that the best outcomes occur when I wait momentarily, being with the person in order to meet them as a fellow human being and then I am able to align my response to them and their situation.

Through using the methodology in the autoethnographic research process, I validated the naturalistic language with which I converse with people as I nurse them. I found that writing my own story drew out my language and memories of situations that can only be described as life challenging in the extreme. While I have used only a few words to indicate the huge events, the text reveals the momentous impact that these events have had on my life and practice. 
Writing my life as a story enabled me to gain a means to observe myself through a narrative gaze; this has given me an awareness of my capacity to use narratives as a foundation to guide my practice assessments, decisions and reflections in critical moments of care.

The second question was: how is compassion used to achieve turning points especially with people who are in or facing extreme crisis situations?

This question, in fact, became the turning point for me in this thesis. By asking it, I was able to consider the nature of compassion and I discovered that I feel able now to engage in such a way that I consciously complete as a circle, because I am caring with compassion. I have found a means of enriching and making my practice more meaningful for myself and I believe more meaningful for my patients as well. I believe that we will bring the importance of compassion in nursing practice back to the forefront if we discuss our stories more with our peers and students, as well as with other members of the health team.

I have given examples through a narrative gaze. I believe these stories and other patients' and nurses' stories should be more readily available for reading and discussion. Benner et al. (2009) write that:

...reading narrative accounts of illness and recovery can augment explanations of disease and pathology and the human experience of living with illness, loss, recovery, and care-all aspects of care so relevant to nurses. (p.373)

\section{Further Research}

Although I have shown how I use a process, I believe that it is too early for me to claim it is a model of practice. I know that I have developed steps that I utilise in my own practice and they work for me. I have had positive feedback from colleagues, as indicated in Chapter Nine, and in time I believe that the steps portrayed will be identifiable as a way of being present in practice when there is life threat and intense, stressful emotional situations.

Perhaps a start has already begun. There is renewed interest in compassion in another healthcare setting in New Zealand. Compassion has been highlighted as the missing ingredient in managed health care by Robyn Youngson (2008) who has set up an organisation 
called Compassion in Health Care. This organisation aims to restore caring and compassion as core values and daily lived practices for all of our health professionals and health institutions

While this new clamour for compassion is refreshing, I believe nurses have to regain their focus on total healing of the patient's being, physical and non- physical. I believe that my thesis has reiterated that compassion can become a way of being in health care and has shown that this way of being does not have a finite dollar component attached to it. Yet this important point can be continuously brought to the attention of those in policy development and health management.

I have heard it said in my own work setting and others that compassion and caring cannot be accurately measured and hence have not been given much traction in quality and risk initiatives. However, this has been challenged by Watson (2009) who describes many tools and assessment scales to measure caring and caring behaviours.

Writing narratives with associated reflections has enabled me to identify special moments that reflect the uniqueness of nursing practice. These insights are lost if they are not discussed with colleagues or written. I am convinced that if these moments where to be described the very core of nursing, its very essence would be visible. These moments are so personal and precious for patients and nurses that I think nurses feel they would almost betray a confidence if they tried to describe them or write about them. I feel that nurses should be encouraged to write more openly about these hidden areas of practice. These core moments of healing are described by Reid (2002, p.15) as "sacred moments," and Reid contends that society is seeking insights through encountering the sacred in life.

\section{Nursing Education}

I believe that there should be further research into how to promote the fact that nursing needs art and science, but so often the technical skills side of nursing appears to take precedence over, for example, the expression of interpersonal skills between nurses and patients and their loved ones. I believe that individually we may have to go back to defining what an expert nurse is or what an expert clinician is and then collectively we can acknowledge this experience 
through articulating it. Benner, et.al. (2009, p. 264) agree with the fact that"... caring practices may not be as valued as highly technical skills." Benner et.al. (2009) highlight this through an example of a nurse's description of what she saw as being an excellent clinician:

...mastering technical skills and handling emergency situations rather than doing highly technical care in relation to particular patients and families- that is, integrating clinical reasoning in transitions with caring knowledge such as teaching, coaching, and comforting patients and families. (p.264)

It is perhaps difficult to envisage trainees in nursing courses spending too much time on compassion and listening in their already crammed curricula but I believe that it is possible to highlight these aspects of expert practice by role modelling. I have found it useful to promote compassion and caring during study days, and to showcase stories which articulate a process for reflecting on compassion and healing in nursing at Nursing Grand Rounds. The challenge is to publish texts and submit conference presentations that articulate this practice.

\section{Complete the Chain of Caring with Compassion}

Based on my own research, I suggest that the ingredient that is essential when planning care protocols and nursing plans to treat patients is compassion. Compassion relates to our humanity in a unique way and the expression of compassion is part of what I identify as essential in critical moments of care, exemplifying the art of nursing. Recognition that there is a cyclical transition process in which a person can be guided through is important. In my practice I have found people commonly state they feel comforted or suspended in time. I believe that this feeling of safety and comfort with another is an embodied recognition that although we are human we are Spirit as well. Fox (1979) sums it up by stating that "compassion is one energy, divine and human" (p.31). That the embodied experience of Spirit leads to healing is recognised by nursing research (Watson, 2008). This healing is recognised by nurse and patient or sometimes the patient's relative or close friend: a connection is made with a gaze of compassion.

This recognition of healing within self and within another human being sustains nurses to continue their passion for caring for those who are ill. It gives meaning to the challenge of 
caring for others. For the nurse, this recognition of healing has to be shared as something that is known as being part of and integral in nursing. Watson (2005) argues "that it is our humanity that both wounds us and heals us and those whom we serve; and in the end, it is only love that matters" (p.199). The more nurses share their stories about compassionate moments they have experienced with their patients, the more informed the body of nursing knowledge will become, as Sandelowski (1994) so succinctly states:

Holistic nursing practice mandates developing expertise in the skills of narrative analysis and (re)construction, skills that help the nurse to recapture what is essentially human in health care. (p.30)

In my experience there can be a feeling of being connected and nurtured by a Being greater than ourselves. Although this Being is not visible this Being can be experienced through a sense of presence, a sense of knowing, a sense of calm, a sense of acceptance, a sense of peace and a sense of love.

Through exploring and reflecting on my stories and the stories of other nurses, I have discovered meaning in my nursing practice. Nursing has also enabled me to discover meaning in my life and the lives of others through compassionate listening. I am then able to share love and receive it as well. In this way, healing takes place for the nurse and the patient within a nurturing and peaceful space. Through nursing practice I have discovered a compassionate way of being in the world.

I feel the words of Helen Keller (as cited in Liehr, 1989, p.7) are the most apt way to conclude my thesis: "The best and most beautiful things in the world cannot be seen or even touched. They must be felt with the heart". 


\section{REFERENCES:}

Barasch, M. I. (2009). The compassionate life. Walking the path of kindness. San Francisco: Berret-Koehler Publishers, Inc.

Bellah, R. N. (1994). Understanding caring in contemporary America. In S. S. B. Phillips, (Ed.), The crisis of care. Affirming and restoring caring practices in the helping professions (pp. 21-35). Washington: Georgetown University Press.

Benner, P. (1984, 2001). From novice to expert. Excellence and power in clinical nursing practice (Commemorative Edition ed.). Upper SaddleRiver: Prentice Hall Health.

Benner, P. (1992). Lamentations. [Poem]. Journal of Christian Nursing, (Summer), 9-11.

Benner, P. (1994). Caring as a way of knowing and not knowing. In S. S. B. Phillips (Ed.), The crisis of care. Affirming and restoring caring practices in the helping professions. Washington: Georgetown University Press.

Benner, P.,Tanner, C., \& Chesla, C. (2009). Expertise in nursing practice. caring, clinical judgement, and ethics.(2nd ed.). New York: Springer Publishing Company.

Benner, P., \& Wrubel, J. (1989). The primacy of caring. Stress and coping in health and illness. Menlo Park: Addison-Wesley.

Brunner, J. (2004). Life as narrative. Social Research, 71(3), 691-710.

Buchanan-Barker, P. B. (2004). More than a feeling. Nursing Standard, 1(1), 18-19.

Burkhart, N. (2006, February 13). Is anyone out there still? Listening? Dental Office Magazine. $\begin{array}{llll}\text { Retrieved } & \text { April, } & 29, & \text { 2009, }\end{array}$ http://www.dentalofficemag.com/display_article/247509/56/none/none/Dept/ls-AnyoneOut-There-Still-Listening 
Burnard, P. M. (1991). Nurses' interpersonal skills: a study of nurses' perceptions. Nurse Education Today, 11, 24-29.

Chiarella, M. (2007).Redesigning models of patient care and organization: building collegial generosity in response to workplace challenges. Australian Health Review, 31 (Supp 1) $101-116$.

Chochinov, H. M. (2006). Dying, dignity, and new horizons in palliative end - of - life care. C A A Cancer Journal for Clinicians, 52 (4) 84-108.

Chodron, P. (2003). Comfortable with uncertainty. Boston: Shambhala.

Clausen, J. A. (1998). Life reviews and life stories. In J. N. E. Giele, (Ed.), Life reviews and life stories. Thousand Oaks: Sage.

Coberly, M. (2002). Sacred passage. How to provide fearless, compassionate care for the dying. Boston: Shambhala.

Daaleman, T.P., \& Elder, G.H (2007). Family medicine and the life course paradigm. Journal of the American Board of Family Medicine, 20, 85-92.

Dowling, M. (2006). The sociology of intimacy in the nurse-patient relationship. Nursing Standard, 20(23), 48-54.

Elias, N. (1985). The loneliness of the dying (E. Jephcott, Trans.). New York: Blackwell.

Ellis, C. (2009). Revision: autoethnographic reflections on life and work. Walnut Creek: Left Coast Press, Inc. 
Ellis, C. (2008). Presentation given at the Fourteenth International Reflective Practice Conference in Rotorua: New Zealand.

Ellis, C. (2004). The ethnographic I. A methodological novel about autoethnography. Walnut Creek: AltaMira Press.

Ellis,C., \& Bochner, A. (2000). Autoethnography, personal narrative, reflexivity. Researcher as subject. In N.K Denzin, \& Y.S Lincoln, (Eds.),Handbook of qualitative research (2nd ed.), (pp. 733-768).

London: Sage Publications, Inc.

Ellis, C., \& Bochner, A. D (Eds.). (1996). Composing ethnography. Alternative forms of qualitative writing. Walnut Creek: AltaMira Press.

Fisher, L. (1982). Ghandi: His Life and Message of the World.

New York: New American Library.

Fox, M. (1979). A spirituality named compassion and the healing of the global village Humpty Dumpty and us. San Francisco; Harper \& Row.

Foster, K., McAllister, M., \& O'Brien, L. (2006). Extending the boundaries: Autoethnography as an emergent method in mental health nursing research. International Journal of Mental Health Nursing. 15, 44-53.

Frankl, F.(1990). Facing the transitoriness of human existence. Generations, 14(4).

Frankl, V. E. (2006). Man's search for meaning. Boston: Beacon Press.

Freshwater, D., Taylor, B., \& Sherwood, G (2008). International textbook of reflective practice in nursing. Oxford: Blackwell Press. 
Gaut, D. A. \& Boykin, A. (Eds.) (1994). Caring as healing: Renewal hrough hope, Storytelling as enquiry . New York: National League for Nursing Press.

Gaut, D. A., \& Leininger, M . M (Eds.) (1991). Caring: The compassionate healer. New York: National League for Nursing Press.

Grant, A. (2010). Autoethnographic ethics and rewriting the fragmented self. Journal of Psychiatric and Mental Health nursing, 17, 111-116.

Hagerty, B. M., \& Patuski, K.L. (2003). Reconceptualizing the nurse-patient relationship. Journal of Nursing Scholarship, 35(2), 145-150.

Holt, N. L. (2003). Representation, legitimation, and autoethnography: An autoethnographic writing story. International Journal of Qualitative Methods, 2 (1), 1-21.

Hudacek, S. S. (2008). Dimensions of caring: A qualitative analysis of nurses stories. Journal of Nursing education, 47(3), 124-129.

Humphreys, M. (2005). Getting personal: Reflexivity and autoethnographic vignettes. Qualitative Inquiry, 11(6), 840-860.

Husted, G. L., \& Husted, J. H. (1995). The bioethical standards: the analysis of dilemmas through the analysis of persons. Advanced Practice Nurse Quaterly, 1 (2), 69-76.

Johns, C. (2006). Engaging reflection in practice. A narrative approach. Oxford: Blackwell Publishing .

Johns, C., \& Freshwater, D. (Eds.) (1998). Transforming nursing through reflective practice. Oxford: Blackwell Science.

Johnstone, M. J. (1999).Bioethics: a nursing perspective. Sydney: Harcourt Saunders. 
Keats, P. Multiple text analyses in narrative research: visual, written and spoken stories of experience. Qualitative Research, 9(2), 181-195.

Kidd, J.D. (2008). Aroha mai: Nurses, nursing and mental illness. Unpublished PhD Thesis. The University of Auckland, Auckland.

Kidd, J.D. \& Finlayson, M. (2009). When needs must: Interpreting autoethnographical stories. Qualitative Enquiry, 15(6). Downloaded from http://qix.sagepub.com at Victoria University of Wellington on September 30, 2009.

Kiesinger, C.E. (2002). My father's Sshoes: The therapeutic value of narrative reframing. In A.P. Bochner \& C. Ellis (Eds.). Ethographically speaking. Autoethnography, literature, and aesthetics (pp.95-114).

Walnut Creek: AltaMira Press.

Kubler-Ross, E. (1969). On death and dying. New York: Routledge.

Kubler-Ross, E. (1997). The wheel of life. A memoir of living and dying. New York: Touchstone Books.

Krieger, D. (2002). Therapeutic touch as transpersonal healing. New York: Lantern Books.

Lantz, J. (2000). Phenomenological reflection and time in Vicktor Frankl's existential psychotherapy. Journal of Phenomenological Psychology, 31(2), 220-231.

Levine, M. A. (2006). Transforming experiences: A reflective topical autobiography of facilitating student nurse development through international immersion programmes. Unpublished PhD Thesis. Victoria University of Wellington, New Zealand. 
Liehr, P. \& Smith, M. J. (1999). Middle range theory: Spinning research and practice to create knowledge for the new millennium. Advanced Nursing Science, 21(4), 81-91.

Lindstrom, U. A., Lindholm, L. \& Zetterlund, J. E. (2006). Theory of caritative caring. In Tomey, A. M \& Alligood, M. R.(Eds.) Nursing Theorists and Their work (Sixth ed.). St.Louis: Mosby.

Maher, J.M. (1999). An exploration of the experience of critical incident stress debriefing on firefighters within a region of New Zealand fire service. Unpublished Master's Thesis. Victoria University of Wellington, New Zealand.

Morrison, P. \& Burnard, P. (1997). Caring and communication. The interpersonal relationship in nursing. (2nd ed.). Hampshire: Macmillan Press Ltd.

Morse, J. (2002). Writing my own experience... Qualitative Health Research, 12(9), 1159-1160.

Morse, J. M., Bottorff, J., Anderson, G., O' Brien, B., \& Solberg, S (2006). Beyond empathy, expanding expressions of caring. Journal of Advanced Nursing, 53(1), 75-87.

Newson, P. (2008). Loneliness and the value of empathetic listening. Nursing \& Residential Care, 8(12), 555-558.

Nordby, H. (2007). Meaning and normativity in nurse-patient interaction. Nursing Philosophy, 8 , 16-27.

Nouwen, J. M., McNeill, D.P. \& Morrison, D.M (1983). Compassion. A reflection on the Christian life. New York: Image Books.

Nursing Council of New Zealand (2007). Code of Conduct for Nurses and Midwives. Retrieved as a pdf on 30 August 2009 from www.nursingcouncil.org.nz 
O'Brien, A. J.,Hughes, F.A. \& Kidd, J.D. (2006). Mental health nursing In New Zealand primary health care. Mental health Nursing, 21(1), 142-152.

Pack, M. (2008) "Back from the edge of the world". Re- authoring a story of Practice with Stress and trauma using Gestalt Theories and Narrative Approaches. Graduate School of Nursing and Midwifery, Victoria University of Wellington: Guilford Press.

Peters, M. A. (2006). Compassion: An investigation into the experience of nursing faculty. International Journal for Human Caring, 10(3), 38-45.

Phanouf, M. C. (1976).The nursing audit: self-regulation in nursing practice. New York: Appleton-Century-Crofts.

Picard, C. (1991). Caring and the story. The compelling nature of what must be told and understood in the human dimensions of suffering. In D.A.Gaut \& M.M.Leininger (Eds.), Caring: The compassionate healer. (pp.89-98). New York: National League for Nursing Press.

Pollock, D. (2009). Beyond Experience. Cultural Studies Critical Methodologies, 9. Retrieved on 24 Oct. 2009 at 23:05 from http://csc.sagepub.com/cgi/reprint/9/5/636

Puchalski, C. M. (2006). A time for listening and caring. Spirituality and the care of the chronically ill and dying. New York: Oxford.

Puckey, T. (2001). Vicarious Traumatization: relevance and implications for psychiatric mental health nursing. Unpublished Masters Thesis. Victoria University of Wellington: New Zealand.

Purnell, M. J. (2006). Nursing as Caring: A model for transforming practice (Sixth ed.). St Louis: Mosby. 
Reid, K. (2002). SACRED MOMENTS: the human-to -human encounter between palliative care nurses and people who are dying. An Unpublished Masters Thesis. Victoria University of Wellington, New Zealand

Roach, S. M. S. (1984). Caring: The human mode of being, Implications for nursing. Toronto: University of Toronto Press.

Roach, S. M. S. (1987). The Human Act of Caring: a blueprint for the health professional. Ottawa: Canadian Hospital Association.

Roach, S. M. S., Gaut., D.A., \& Leininger, M.M (Eds) (1991). Caring: the compassionate healer. New York: National League for Nursing Press.

Sandelowski, M. J. (1994). We are the stories we tell: Narrative knowing in nursing practice. Journal of Holistic Nursing, 12(1), 23-33.

Schantz, M. L. (2007). Compassion: A concept analysis. Nursing Forum, 42(2), 48-55.

Seikkula, J. \& Trimble, D. (2005). Healing elements of therapeutic conversation: Dialogue as an embodiment of love. Family Process, 44(4), 461-475.

Shaw, H. K. \& Degazon, C. (2008). Integrating the core professional values of nursing: A profession, not just a career. Journal of Cultural Diversity, 15(1), 44-50. Downloaded from Cinahl Database through Victoria University of Wellington at 11:57 on 26 October, 2009.

Smith, B. (1999). The abyss: Exploring depression through a narrative of the self. Qualitative Inquiry, 5(2), 264-279.

Stickley, T. \& Freshwater. D. (2006). The art of listening in the therapeutic relationship. Mental Health Practice, 9(5), 12-18. 
Schweitzer, A. (1998). Out of my life and thought. (Translated by Lemke, A.J.) Baltimore: The John Hopkins University Press.

Tanner, C. A., Benner, P.,Chelsa, C. \& Gordon, D.R. (1993). The phenomenology of knowing the patient. Journal of Nursing Scholarship, 25(4), 273-280.

Thilmann-Healy, L. M. I. E., C. \& Bochner, A.P (eds,) (1996). Composing ethnography. Alternative forms of qualitative writing (Vol. 1). Walnut Creek, California: AltaMira Press.

Travelbee, J. (1971). Interpersonal aspects of nursing (2 Ed.). Philidelphia: F. A. Davis Company.

Vachon, M. (1987). Occupational stress in the care of the critically ill, dying and the bereaved. New York: Hemisphere.

Van Manen, M. (1998). Modalities of body experience in illness and health. Qualitative Health Research, 8(1) 7-24.

Vickers, M. (2002). Researchers as storytellers: Writing on the edge - and without a safety net. Qualitative Inquiry, 8(5), 608-621.

von Dietze, E., \& Orb., A. (2000). Compassionate care: a moral dimension of nursing. Nursing Inquiry, 7, 166-174.

Watson, J. (1999). Nursing: Human science and human care: a theory of nursing. New York: National League for Nursing.

Watson, J. (2004).Caring science as sacred science.

Philadelphia: F. A. Davis. 
Watson, J. (2005). Love and caring. Ethics of face and hand-an invitation to return to the heart and soul of nursing and our deep humanity. Nursing Administration Quarterly, 27(5), 197-202.

Watson, J. (2008). Nursing: The philosophy of science and caring. (Revised ed.). Bolder: University Press of Colorado.

Wayman, L. M., \& Gaydos L.H.B. (2005). Self-transcending through suffering. Journal of Hospice and Palliative Nursing, 7(5), 263-270.

Wilkinson, M. J. (1995). Love is not a marketable commodity: new public health management in the British National Health Service. Journal of Advanced Nursing, 21, 980-987.

World Health Organisation. (2002). Definition of Palliative Care. Retrieved from http://www.who.int/cancer/palliative/definition/en/

Wright, S. (2007). Powerful presence. Nursing Standard, 22(10), 24-25.

Youngson, R. (2008). Compassion in healthcare. Future Debate (Paper 2), 1-8. 